\title{
sciendo
}

\section{THE DIET, AND PELLET RESIDUE TAPHONOMY, of BARn Owls Tyto alba ON A GREEK ISLAND REVEALS}

AN EXCEPTIONAL DIVERSITY OF AVIAN PREY

\section{Prehrana in tafonomija ostankov izbljuvkov pegaste sove Tyto alba na grškem otoku razkriva izjemno raznolikost ptičjega plena}

\author{
Anthony S. Cheke ${ }^{1}$, Julian P. Hume ${ }^{2}$ \\ 139 Hurst Street, GB-OX41HE Oxford, UK, e-mail: anthony.cheke@dodobooks.com \\ 2 Bird Group, Department of Life Sciences, Natural History Museum, Akeman St, Tring, GB-HP23 6AP Herts, UK, \\ e-mail: j.hume@nhm.ac.uk
}

Barn Owl Tyto alba pellets and loose bones on a cave floor from Amorgos (Cyclades, Greece) were examined and the birds found to have caught at least 39 species of bird, mostly identified from humeri, plus shrews Crocidura suaveolens, a few lizards and dung beetles, in addition to their principal diet of rodents (rats Rattus rattus, mice Apodemus spp. \& Mus musculus). Amongst the birds, migrants appeared most vulnerable to owl predation, with some notable exceptions, while resident species were under-represented. The range of bird species found appears to be the largest recorded for any Barn Owl study of a single site. Considerable differences were found in species proportions of taxa in fresh pellets and in loose bones, probably due to differential rates of degradation. Photographs of all humeri are included to aid identification in other studies.

\section{Introduction}

The diet of owls is well studied due to the ease of analysing the pellets they eject of undigested vertebrate bones and invertebrate exoskeletons, and the food habits of the geographically widespread Barn Owl Tyto alba are among the best known (e.g. Bunn et al. 1982, TAYlor 1994, Romano et al. 2020). In Barn Owls, small mammals almost invariably make up the majority of food items in both numbers and biomass, but reptiles and birds are also taken, and in some circumstances the latter can make a significant contribution. Here we report on the remarkable variety of avian species taken by Barn Owls on Amorgos, a small island $\left(121 \mathrm{~km}^{2}, 33 \mathrm{~km}\right.$ long by $6 \mathrm{~km}$ at the widest point) in the Cyclades/ Kiklades southeast of Naxos in the Aegean.
As part of wider studies on the fauna of Amorgos (Cheke \& Ashcroft 2017, Cheke et al. 2020), during 2015-2019 Barn Owl roosts in small caves and cavities notified to ASC by locals were examined by ASC and Ruth Ashcroft (REA) for intact pellets and loose bones on cave floors; owl prey has not previously been studied on Amorgos. Thirty-nine whole pellets were collected from three locations, and hundreds of bones retrieved from the floor of one cave, with a few from a fourth site (see below). The sites are not occupied continuously by the owls, and there appears to have been a decline to near extinction of these owls on the island in the last decade, probably related to poisoning of rats $-\mathrm{a}$ dead owl with no signs of injury was found by local tour guide Lonaïs Jallais in 2015. We found no recent (post 2015) pellets in 2016 or 2017, though 
A. S. Cheke, J. P. Hume: The diet, and pellet residue taphonomy, of Barn Owls Tyto alba on a Greek island reveals an exceptional diversity of avian prey

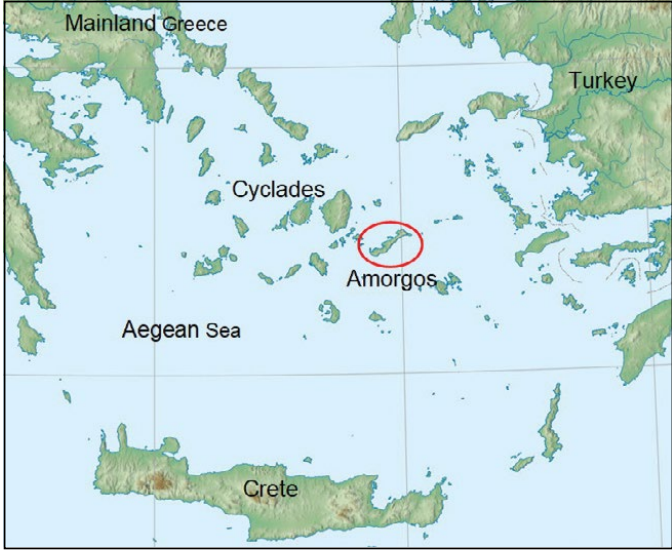

Figure 1: Location map of Amorgos (circled) in the eastern Aegean sea.

Slika 1: Lokacija otoka Amorgos (obkroženo) v vzhodnem Egejskem morju.

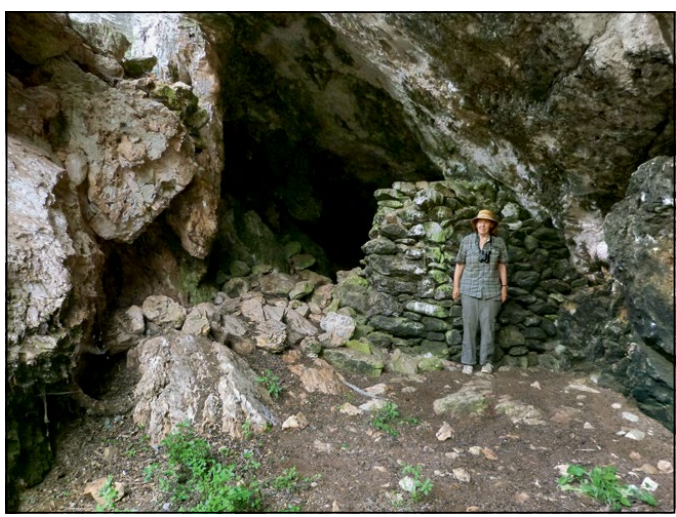

Figure 3: Photo of entrance to Site D (Dhri cave), with REA at the location of the main Barn Owl pellet deposit. Barn Owl excreta is visible on the stone wall to the left of REA. The loose bones were found on the cave floor in the foreground.

Slika 3: Fotografija vhoda na lokaliteto D (jama Dhri); REA označuje lokacijo glavnega nahajališča izbljuvkov pegaste sove. Na zidu levo od REA so vidni sovini iztrebki. Posamezne kosti so bile najdene na jamskih tleh (v ospredju fotografije).

three, still wet, were collected in April 2018, although the owl was not seen. Only an old dry pellet was found in 2019, and indeed most pellets we recovered were dry with no indication of when they had been produced.

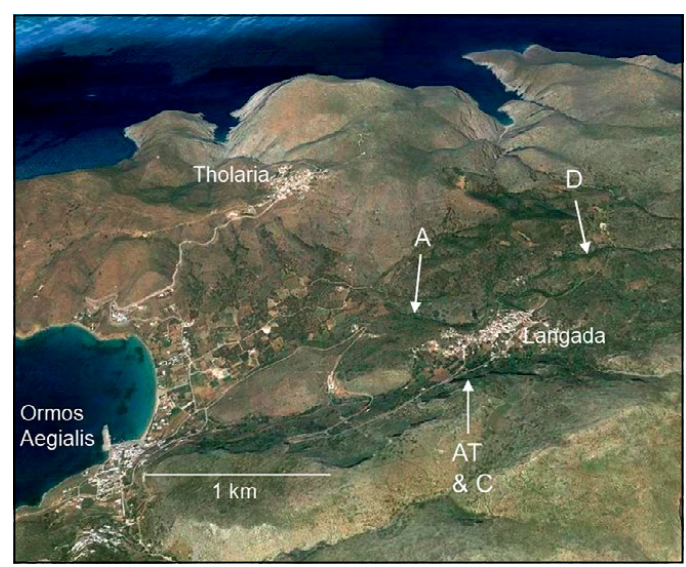

Figure 2: Google Earth panoramic view of the Aegiale area, northeastern Amorgos, with location of Barn Owl sites indicated.

Slika 2: Google Earthov panoramski pogled območja Aegiale, severovzhodni Amorgos, z oznakami lokacij pegastih sov.

The four collection localities are all fairly close together around the village of Langada in the Aegiale area in the north-east of Amorgos (Figure 2). This part of the island consists of part-metamorphosed Triassic-Eocene limestone bedrock ('massive marble', Rosenbaum et al. 2007), with numerous cavities and some caves. The area is also the wettest part of the island with the richest vegetation, a maquis that is almost forest in parts of the area between Langada to Theologos, and consequently has the highest bird diversity throughout the year (CHeke et al. 2020; see Table 5 for status of prey species). The principal site (D; Figure 3 ), about 1 $\mathrm{km} \mathrm{NE}$ of the village at Dhri, is a small cave in the wall of a wooded gorge, with a roost site on a drystone wall near the entrance - there is no evidence that the owls penetrate into the true interior. On a cliff above and just south of the village is the shrine of Aghia Triada (AT), were the owls used to nest (local informants, pers. comm. to ASC) but since c. 2010 now only used sporadically for roosting. Just NW, and as the Arakalos gorge opens out below the village, is a larger cave (A) in a cliff somewhat difficult of access where we only collected pellets once. Finally, south and up the talus slope from AT is a rock cleft (C) where ASC first found bones, but only a few, and not subsequently visited. 


\section{Methods}

Whole pellets were simply picked up from the floor of a site, dried in the sun or oven, and preserved in ziplock bags for later analysis in Oxford, UK. The bones were separated out in water and all bones and invertebrate remains removed, sorted and identified to major taxa (birds, lizards) or species (mammals) by ASC or Linda Losito (dung beetles). Rodents were identified to genus using Lawrence \& Brown (1973), its clear and extensive diagrams not superceded by more recent guides; only one species each of Rattus and Mus are found on Amorgos (Cheke \& Ashcroft 2017), and the two Apodemus species are separated by non-overlapping overall jaw size (ibid.), confirmed by the relatively larger tooth roots in $A$. mystacinus. Shrew bones were presumed to be from the only known species on the island, Crocidura suaveolens (CHEKE \& AsHCROFT 2017). Gecko Mediodactylus (Cyrtopodion) kotschyi dentaries were identified from Villa et al. (2018), differing larger non-gekkonid lizard jaws assumed to be from the abundant wall lizard Podarcis erhardii, the only possibly candidate (CHEKE \& AsHCROFT 2017). Bird names and sequence follow the standard English-language handbook of Greek birds (HANDRINOS \& AKRIOTIS 1997), with, in tables, more recently revised names in brackets where relevant. Pellets and whole skulls on the cave floor were often host to larvae of tapestry moths Trichophaga tapetzella and clothes moths Tinea bisselliella, revealed when the adults emerged in the ziplock bags.

The floor of cave $\mathrm{D}$ between the entrance and the roosting rock, semi-open to the elements, proved to be rich in bones from prey. The cave is used by goats so the bones from decayed pellets were scattered over several square metres of ground, but only in the top couple of centimetres after the layer of goat droppings was removed. Digging deeper revealed no further bones. Collections, made by carefully surveying and raking through the surface layer, were made on several occasions during 20152019 until the site was more or less worked out. There was no new owl-generated input over this period until four fresh pellets (birdless) were found in March 2018, and a partial fifth in April 2019, but old and including a bird, probably dating from the same batch. All bones found, including very small ones, were collected directly into ziplock bags, then sorted into major taxa back at ASC and REA's pied-á-terre in Langada, for later more specific identification by ASC in Oxford.

Birds (humeri, skull elements) were provisionally identified by ASC in Oxford using published material (principally Jánossy 1983, BROWN et al. 1987 and online skullsite.com), but later rechecked together with JPH against reference material in the skeleton collection at the bird section of the Natural History Museum, Tring, UK (NHMUK). To aid the preliminary identifications a table of bone measurements of European birds in the size range found was compiled from the literature (available from the first author on request).

\section{Results}

Both by number ( $72 \%$ of loose bones, $82 \%$ in pellets) and biomass the main prey of the Amorgos Barn Owls were the four rodents present on the island Black Rats Rattus rattus, some Rock Mice Apodemus mystacinus, many remains assigned provisionally to Wood Mice Apodemus sylvaticus, and a few House Mice Mus musculus. In addition to birds, other prey were frequent shrews Crocidura suaveolens, a very few lizards (Reptilia - Squamata), beetles (Coleoptera) and one unidentified dragonfly (Odonata) (Tables $1 \& 2$, CheKe \& Ashcroft 2017).

Brown Rats $R$. norvegicus and voles Cricetidae, common prey in mainland Europe, are absent from Amorgos (Masseti 2012, Cheke \& AshCroft 2017).

The proportions of the various prey species amongst loose bones and pellets are strikingly different, and very significantly so on a $\chi^{2}$ test (Table 3 ); possible reasons for this are discussed below.

Both in pellets (Table 1) and in the loose bones on the cave floor (Table 2) there was a small but significant proportion of bird remains. Amongst the floor bones, humeri were the most frequent and generally the best preserved avian bones recovered (Table 4), and these are also the most diagnostic to species in the absence of complete skulls (Jánossy 1983). The bird bones proved on study to come from a surprisingly wide range of species, although many were represented by only one or a few individuals. Overall a total of 39 species (Table 5, Figure 4 $\& 5)$ were recorded; in addition to loose bones, 
A. S. Cheke, J. P. Hume: The diet, and pellet residue taphonomy, of Barn Owls Tyto alba on a Greek island reveals an exceptional diversity of avian prey

there were eleven more or less complete associated skeletons in pellets (Table 4), including a Siskin Carduelis (Spinus) spinus (Fig. 8), the only species not represented in the loose bones on the cave floor.

The birds taken by the Barn Owls range from the very small (Chiffchaff Phylloscopus collybita) to quite bulky (Blackbird Turdus merula), a weight range of 6-10 to $80-125 \mathrm{~g}$, though birds in the lower part of this range $(15-25 \mathrm{~g})$ predominate (Table 4; weights from Snow \& Perrins 1998). All birds taken are passerines, except for Wryneck Jynx torquilla, which is, apart from Common Quail Coturnix coturnix, the only non-passerine (occasional waders excepted) recorded on the island in the same size range as the other prey (CHEKE et al. 2020).

\section{Discussion}

\subsection{Birds}

All but one of the bird species identified in remains has been recorded live on the island by ASC and REA (CHEKe et al. 2020) in the years since 2007. Some however occur infrequently, and in one case, Siskin, bones were identified in a pellet before living birds had been seen, and Wryneck humeri were found (though not identified) before a sight record. The cave floor produced a single Crossbill Loxia curvirostra humerus - a species not yet seen on the island, although known (but accidental) on nearby Iraklia (GAVALAS 2014).

We believe owl prey was taken on Amorgos itself, not brought in from outside. In Greece most Barn Owls are resident, with a small number of immigrants from further north (HANDRINOS \& AKriotis 1997). Home ranges in the Mediterranean area appear not to have been studied, but further north in Europe most birds range c. $3 \mathrm{~km}$ from their roosts, rarely to $16 \mathrm{~km}$ (TAYLOR 1994,2002 ). The only confirmed cases of regular foraging across sea gaps we have found are in the Balearic islands, where owls cross up to $4.5 \mathrm{~km}$ of sea to forage on adjacent islands (GUERRA et al. 2014) and on Skomer Island (Wales, UK; LougHran 2006) where the sea gap to the mainland is only $0.6 \mathrm{~km}$. On Amorgos the over-sea distance to the nearest potentially useful island is greater $(6.6 \mathrm{~km}$ across sea to Ano Antikeri), and it is a further $24 \mathrm{~km}$ (overland) from the cave site; in the other direction it is $7.8 \mathrm{~km}$ over land + $6.8 \mathrm{~km}$ over sea to Liadi - in any case both are little more than rocky outcrops and it is a lot further to islands with suitable habitat. It is thus most unlikely that any but a tiny proportion of bones will have been brought in from outside Amorgos.

The list of birds taken is by no means a random set of the island's small and medium passerines. The bulk of the avian prey consists of migrants - summer visitors, passage migrants and winter visitors, as indicated in Table 4. Resident species in the relevant size range are noticeably under-represented, the most abundant (Sardinian Warbler Sylvia melanocephala, House Sparrow Passer domesticus, and Crested Lark Galerida cristata) barely making the list, and Blue Rock-thrush Monticola solitarius not showing up at all; some residents that are preyed on are species supplemented by more abundant winter visitors (Stonechat Saxicola rubicola, Goldfinch Carduelis carduelis, Linnet Carduelis (Linaria) cannabina, Chaffinch Fringilla coelebs). This suggests the migrants are relatively naïve or vulnerable to Barn Owl predation, whereas the residents are more aware of the threat. Migrants from mainland areas will rarely have been subject to predation from Barn Owls, and in addition may on arrival be exhausted or weak and thus easy targets. We presume the owls catch the birds at night when roosting. There are anomalies however - in both spring and autumn migration Spotted Flycatchers Muscicapa striata can be the most abundant birds in the better vegetated parts of the island, yet they largely escape predation, whereas the less abundant, albeit still fairly common, Pied and Collared Flycatchers Ficedula bypoleuca/F.albicollis, indistinguishable osteologically, are rather frequent victims. Other common migrants that the owls do not

Please note: The following bone photo sets (Figs 4-7) are composites made up of photos of pairs of bones photographed separately. Therefore, the scale bar should be taken as a guide only; more exact measurements can be found in Table 5, column 2 .

Opomba: Sledeče zbirke fotografij kosti (slike 4-7) so kolaži fotografij parov kosti, ki so bili fotografirani posamično. Merilo je zato zgolj vodilo, podrobne meritve so $v$ tabeli 5. 


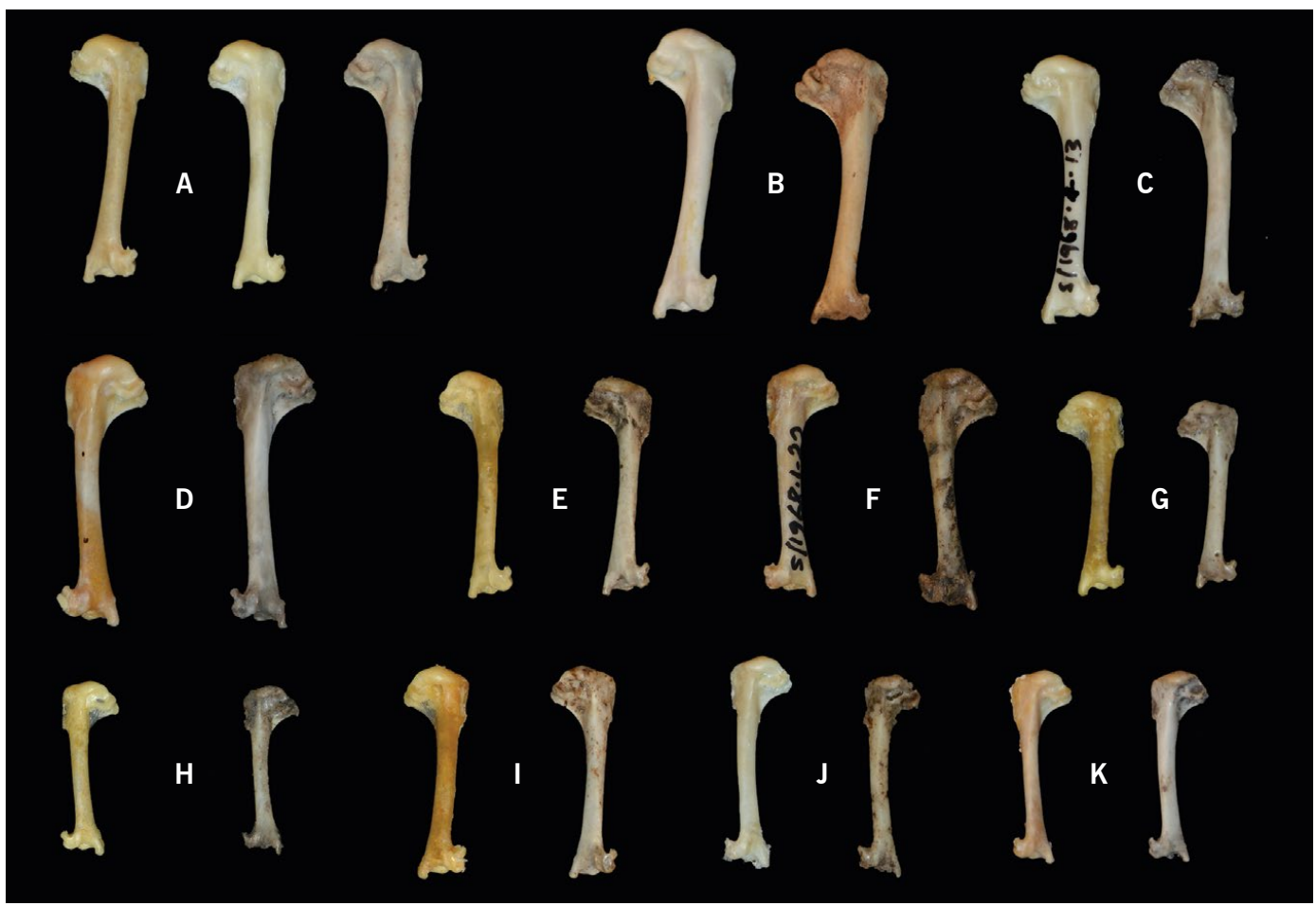

Figure 4: Humeri in caudal view of passerines (warblers \& chats) discussed in the text. In this and subsequent figures (Figure 5, 6 and 7) the left-hand image(s) with numbered codes are reference material from the UK Natural History Museum (NHM), the right-hand bones, labelled Amorgos, are samples collected in this study. In the list the individual bone captions are separated by vertical line 'I'. A - Blackcap Sylvia atricapilla NHMUK S/1968.6.36 u/s I Garden Warbler Sylvia borin NHMUK S/1968.6.28 \& I Amorgos, B - Great Reed Warbler Acrocephalus arundinaceus NHMUK S/1998.92.22 u/s I Amorgos*, C - Nightingale Luscinia megarhynchus NHMUK S/1968.4.13 9 I Amorgos, D - Orphean Warbler Sylvia hortensis** NHMUK S/1968.6.24 ô I Amorgos, E - Common Whitethroat Sy/via

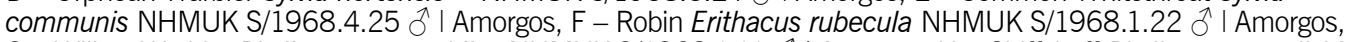
G - Willow Warbler Phylloscopus trochilus NHMUK S/1968.1.11 § I Amorgos, H - Chiffchaff Phylloscopus collybita NHMUK S/1968.1.20 ô I Amorgos, I - Sedge Warbler Acrocephalus schoenobaenus NHMUK 1930.3.24.457 u/s I Amorgos, J - Sardinian Warbler Sylvia melanocephala NHMUK S/1998.29.2 u/s I Amorgos, K - Subalpine Warbler Sylvia cantillans** NHMUK S/2002.40.1 u/s I Amorgos. Scale bar $=10 \mathrm{~mm}$.

* The Amorgos humerus in 'B' is not a Great Reed Warbler, but inferred to be from a Olive Tree Warbler Hippolais olivetorum on the basis of size and morphology (our comparisons and J.Kessler pers. comm.); there being no specimens of $\mathrm{H}$.olivetorum in the NHM skeleton collection we used the bone that came nearest in size and appearance. ** S.(h.) hortensis and the eastern form S.(h.) crassirostris are not separated in the NHM skeleton collections, and are almost certainly indistinguishable; the same applies to the forms/species of the S. cantillans complex.

Slika 4: Nadlahtnice (kavdalno) pevk (trstnice in taščice), omenjenih v besedilu. $\vee$ tej in sledečih tabelah (tabele 5,6 in 7) so na levi strani referenčni primerki iz NHM, na desni, označeni Amorgos, pa primerki iz te raziskave. $V$ opisu slik so posamezne vrste ločene s pokončno črto "I".A - Črnoglavka Sylvia atricapilla I vrtna penica Sylvia borin | Amorgos, B - rakar Acrocephalus arundinaceus | Amorgos, ${ }^{*} \mathrm{C}$ - slavec Luscinia megarhynchus | Amorgos, D svetlooka penica Sylvia hortensis | Amorgos, ${ }^{* *}$ E - rjava penica Sylvia communis | Amorgos, F - taščica Erithacus rubecula | Amorgos, G - severni kovaček Phylloscopus trochilus I Amorgos, H - vrbji kovaček Phylloscopus collybita | Amorgos, I -bičja trstnica Acrocephalus schoenobaenus | Amorgos, J - žametna penica Sylvia melanocephala | Amorgos, K - taščična penica Sylvia cantillans | Amorgos, ${ }^{* *}$ Merilo $=10 \mathrm{~mm}$.

* Nadlahtnica B ne pripada rakarju, vendar na podlagi velikosti in morfologije najverjetneje oljčnemu vrtniku Hippolais olivetorum (lastna primerjava in osebna komunikacija z J. Kassler). V zbirki NHM ni oljčnega vrtnika, zato smo uporabili kost, ki mu je po velikosti in videzu najbolj podobna.

** svetlooka penica S. hortensis in vzhodna svetlooka penica S. crassirostris v zbirki okostji NHM nista ločeni in ju ni mogoče razlikovati. Enako velja za vrsto oz. obliko taščične penice S. cantillans. 


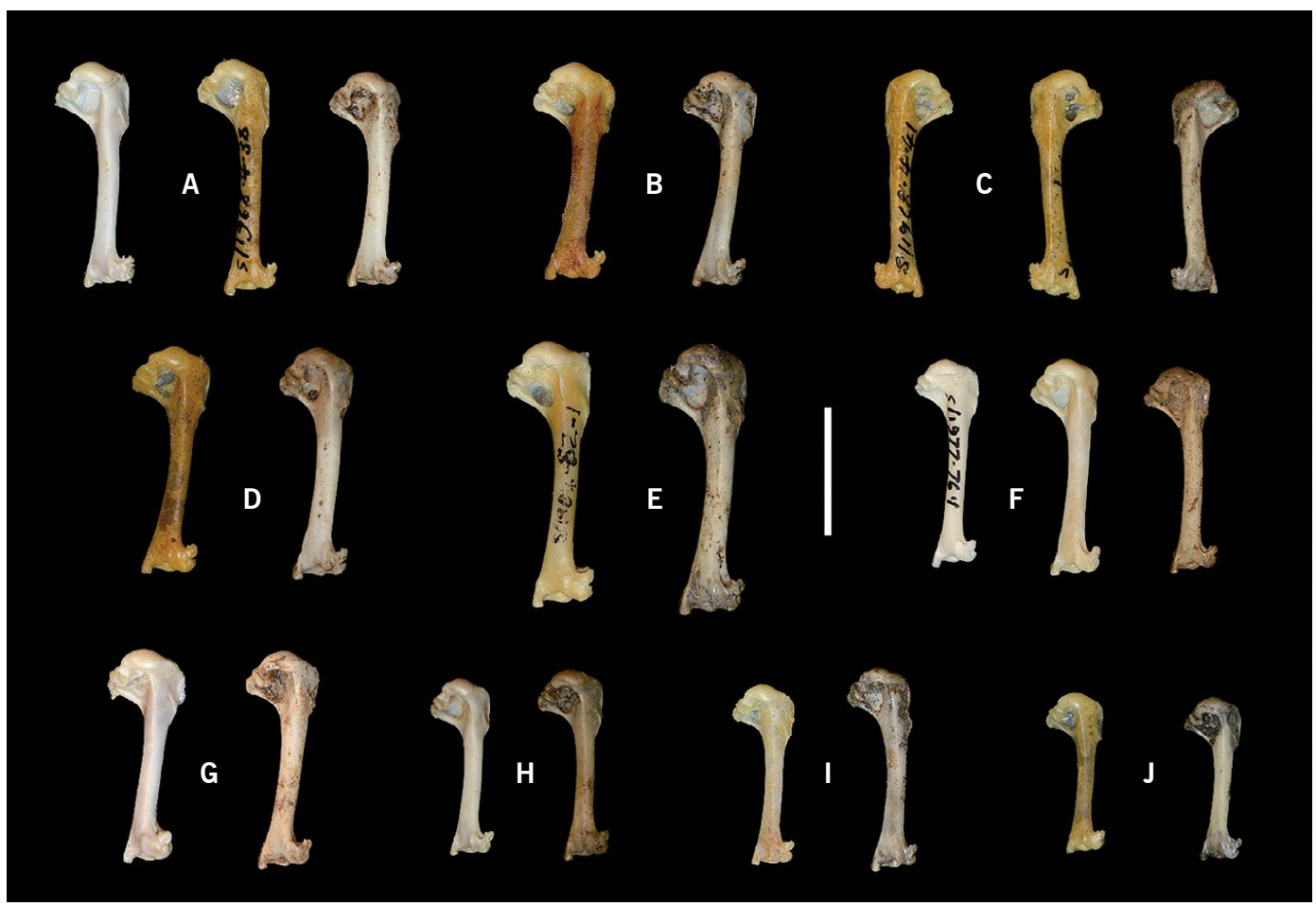

Figure 5: Humeri in caudal view of passerines (finches, buntings \& sparrows) discussed in the text. A - Chaffinch Fringilla coelebs NHMUK S/1968.4.38 \& I Brambling Fringilla montifringilla NHMUK S/1976.20.1 u/s I Amorgos, B - Crossbill Loxia curvirostra NHMUK S/2008.6.1 u/s I Amorgos, C - Ortolan Bunting Emberiza hortulana NHMUK S/1968.4.39 ㅇ I Cretzchmar's Bunting Emberiza caesia NHMUK S/1968.4.41 §̊ I Amorgos, D Greenfinch Carduelis chloris NHMUK S/1982.22.2 u/s I Amorgos, E - Hawfinch Coccothraustes coccothraustes NHMUK S/1984.82.1 $\hat{\jmath}$ | Amorgos, F - House Sparrow Passer domesticus NHMUK S/1977.76.1 u/s I Spanish Sparrow Passer hispaniolensis NHMUK S/1968.1.41 O I Amorgos*, G - Linnet Carduelis (Linaria) cannabina NHMUK S/1976.26.1 đ̊ | Amorgos, H - Goldfinch Carduelis carduelis NHMUK S/2017.8.2 O I Amorgos, I Serin Serinus serinus NHMUK S/1961.13.30 ${ }^{\lambda}$ I Amorgos**, J - 31. Siskin Carduelis (Spinus) spinus NHMUK $\mathrm{S} / 1982.40 .1$ o $\mid$ Amorgos. Scale bar $=10 \mathrm{~mm}$.

* Note the marked difference in morphology between House and Spanish Sparrow humeri, presumably reflecting the greater muscle mass required in the migratory Spanish Sparrow; Amorgos sparrow humeri are clearly from House Sparrows, although a mandible is from a Spanish Sparrow.

** The Serin from Amorgos is very much in the upper end of the size range for the species.

Slika 5: Nadlahtnice (kavdalno) pevk (ščinkavci, strnadi in vrabci), omenjenih v besedilu. A - ščinkavec Fringilla coelebs I pinoža Fringilla montifringilla | Amorgos, B - krivokljun Loxia curvirostra | Amorgos, C - vrtni strnad Emberiza hortulana | balkanski strnad Emberiza caesia | Amorgos, D - zelenec Chloris chloris | Amorgos, E dlesk Coccothraustes coccothraustes I Amorgos, F - domači vrabec Passer domesticus I travniški vrabec Passer hispaniolensis | Amorgos, * G - repnik Carduelis (Linaria) cannabina | Amorgos, $\mathrm{H}$ - lišček Carduelis carduelis | Amorgos, I - grilček Serinus serinus | Amorgos, ** J - čižek Carduelis (Spinus) spinus | Amorgos. Merilo = 10 mm. * Opazna morfološka razlika v nadlahtnici domačega in travniškega vrabca, ki je najverjetneje posledica večje mišične mase slednjega, ki je selivec. Nadlahtnice z otoka Amorgos nedvomno pripadajo domačemu vrabcu, najdene spodnje čeljusti pa travniškemu vrabcu.

** Grilček z otoka Amorgos dosega zgornjo mejo velikosti za to vrsto. 


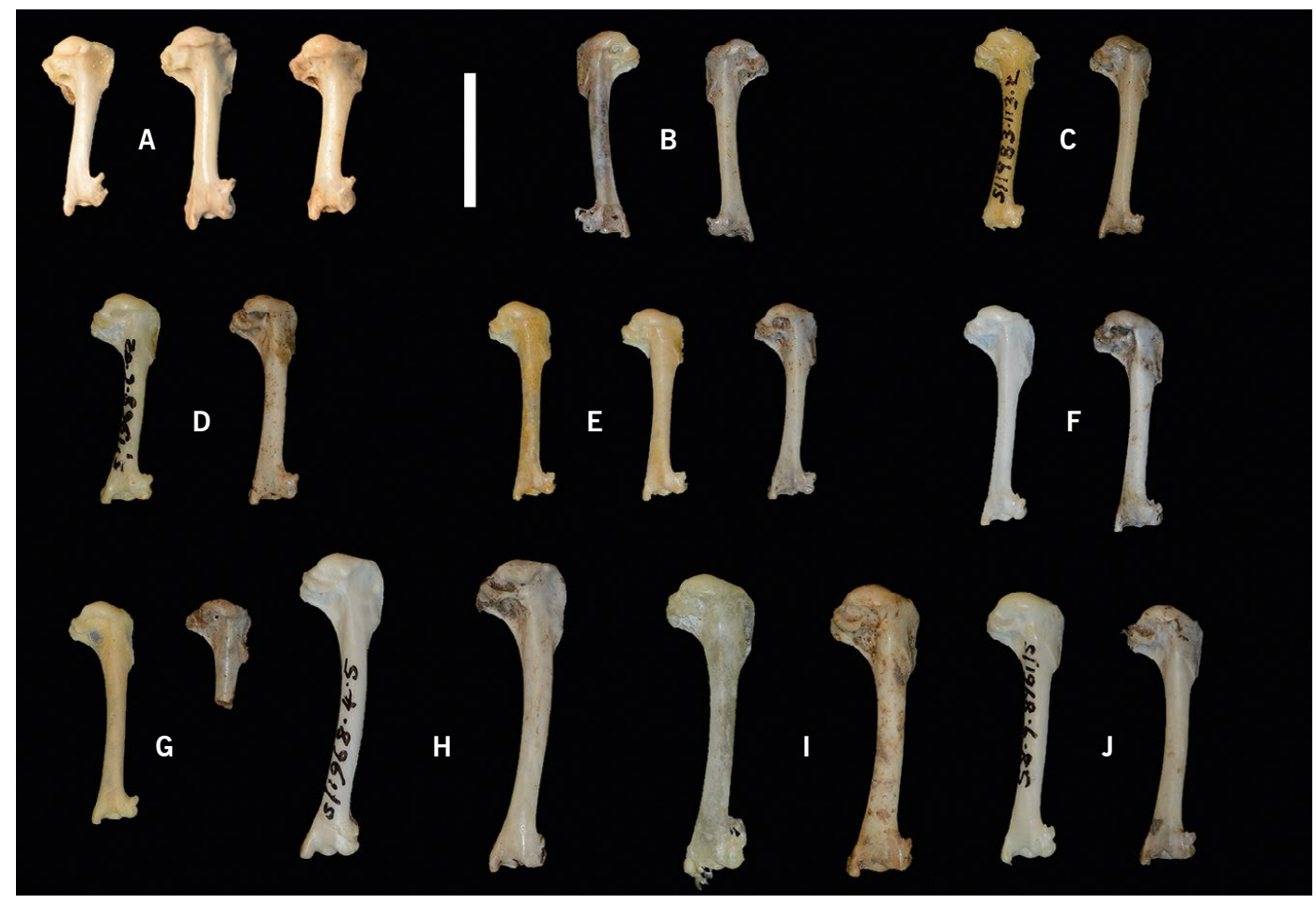

Figure 6: Humeri in caudal view of passerines discussed in the text. A - House Martin Delichon urbica NHMUK S/1973.29.3 u/s I Barn Swallow Hirundo rustica NHMUK S/1985.7.1.237 స̃ I Amorgos*, B - Stonechat Saxicola (torquata) rubicola ** NHMUK S/1968.1.28 ô I Amorgos, C - Whinchat Saxicola rubetra NHMUK S/1983.113.2

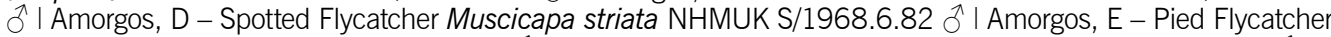
Ficedula hypoleuca NHMUK S1968.6.45 ô I Collared Flycatcher Ficedula albicollis NHMUK S1968.6.79 §ิ | Amorgos, F - Black Redstart Phoenicurus ochrurus NHMUK S/1968.4.12 ô I Amorgos, G - Dunnock Prunella modularis NHMUK S/1996.50.6 ô I Amorgos, H - Wryneck Jynx torquilla NHMUK S/1968.4.5 q I Amorgos, I - Woodchat Shrike Lanius senator NHMUK S/1983.41.1 u/s I Amorgos, J - Red-backed Shrike Lanius collurio NHMUK S/1968.6.85 के | Amorgos. Scale bar = 10mm.

* Although both species are common migrants, Amorgos hirundine humeri are clearly from House Martins not Swallows.

** The segregates in the Saxicola torquata complex are not separated in the NHM skeleton collections.

Slika 6: Nadlahtnice (kavdalno) pevk, omenjenih v besedilu. A - mestna lastovka Delichon urbica I kmečka lastovka Hirundo rustica | Amorgos, ${ }^{*}$ B - prosnik Saxicola (torquata) rubicola I Amorgos, ${ }^{* *}$ C - repaljščica Saxicola rubetra | Amorgos, D - sivi muhar Muscicapa striata | Amorgos, E - črnoglavi muhar Ficedula hypoleuca I belovrati muhar Ficedula albicollis | Amorgos, F - šmarnica Phoenicurus ochrurus | Amorgos, G - siva pevka Prunella modularis | Amorgos, $\mathrm{H}$ - vijeglavka Jynx torquilla | Amorgos, I - rjavoglavi srakoper Lanius senator I Amorgos, J - rjavi srakoper Lanius collurio I Amorgos. Merilo $=10 \mathrm{~mm}$.

* Čeprav sta obe vrsti pogosti selivki, pripadajo najdene nadlahtnice mestnim lastovkam.

** Oblike in podvrste Saxicola torquata v zbirki okostji NHM niso ločene. 


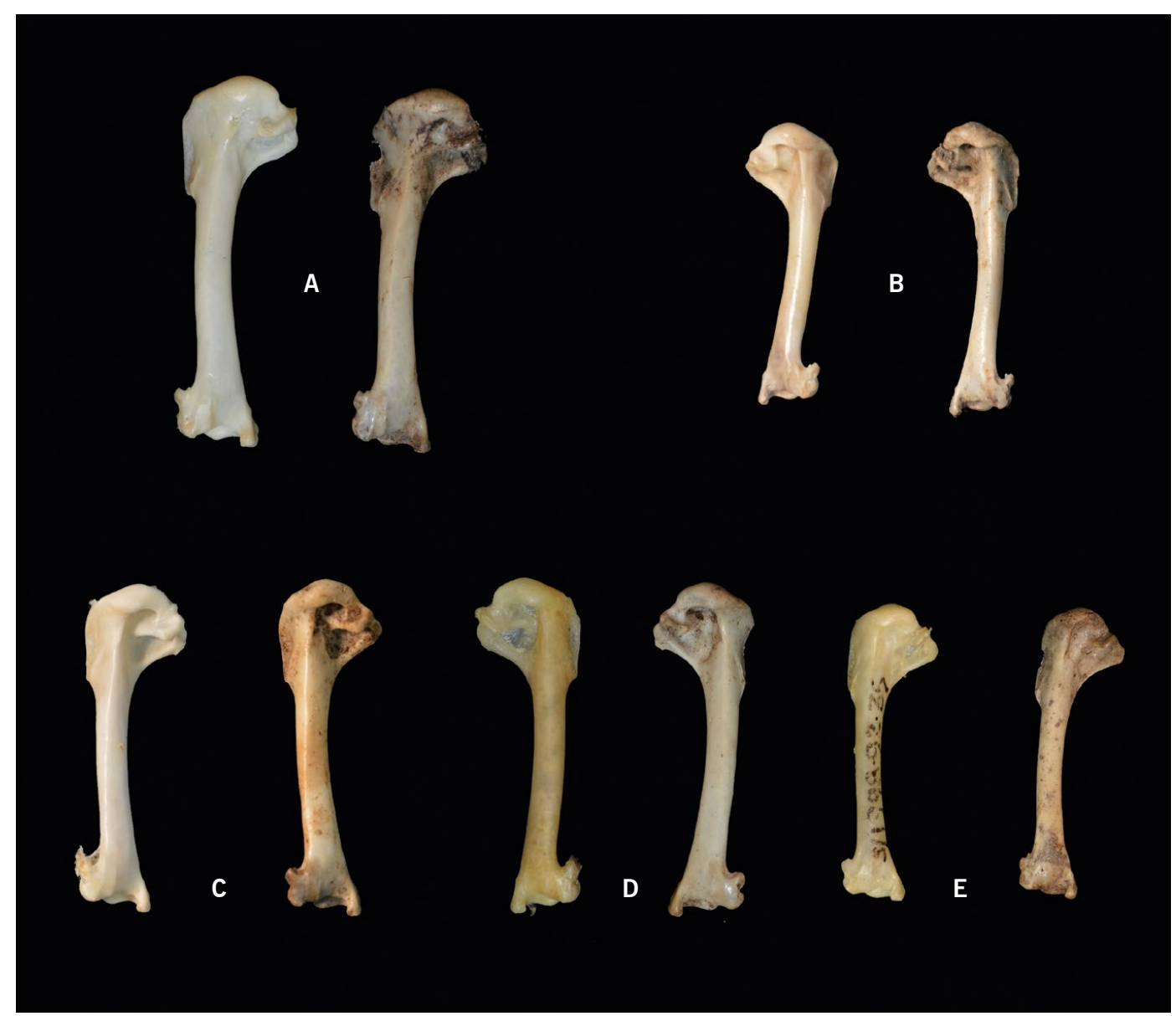

Figure 7: Humeri in caudal view of the largest passerines discussed in the text. A - Golden Oriole Oriolus oriolus NHMUK S/1968.6.10 స̂ | Amorgos, B - Starling Sturnus vulgaris NHMUK S/1973.46.1 O | Amorgos, C - Blackbird Turdus merula NHMUK S/1982.134.1 ô | Amorgos, D - Songthrush Turdus philomelos NHMUK S/1982.48.1 u/s I Amorgos, E - Crested Lark Galerida cristata NHMUK S/1998.92.35 u/s | Amorgos. Scale bar $=10 \mathrm{~mm}$.

Slika 7: Nadlahtnice (kavdalno) večjih pevk, omenjenih v besedilu. A - kobilar Oriolus oriolus | Amorgos, B - škorec Sturnus vulgaris I Amorgos, C - kos Turdus merula | Amorgos, D - cikovt Turdus philomelos | Amorgos, E - čopasti škrjanec Galerida cristata | Amorgos. Merilo $=10 \mathrm{~mm}$. 


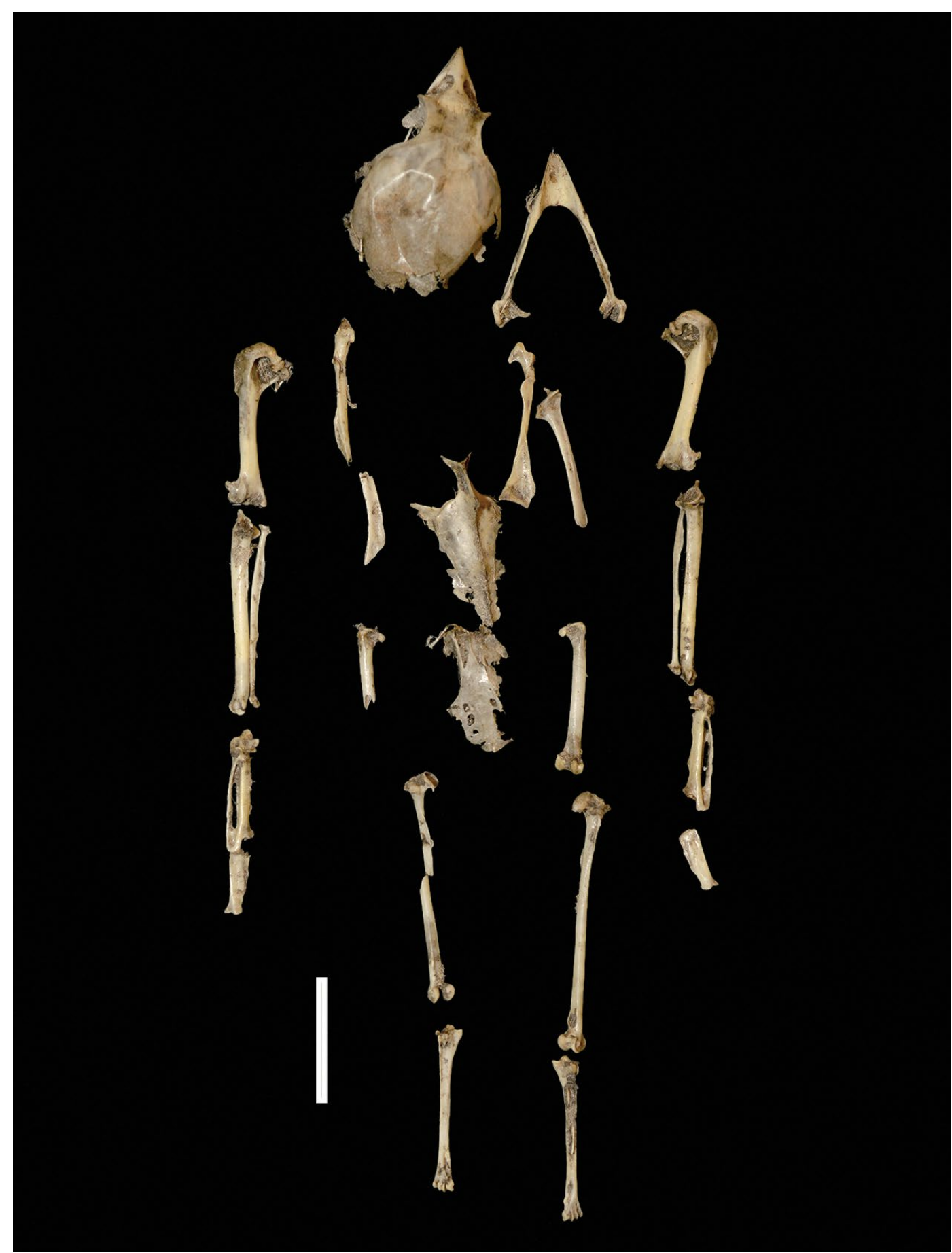

Figure 8: An associated Siskin Carduelis (Spinus) spinus recovered from a single Barn Owl pellet. Scale bar = 10mm.

Slika 8: Okostje čižka, sestavljeno iz enega samega izbljuvka pegaste sove. Merilo $=10 \mathrm{~mm}$. 
A. S. Cheke, J. P. Hume: The diet, and pellet residue taphonomy, of Barn Owls Tyto alba on a Greek island reveals an exceptional diversity of avian prey

Table 1: Barn Owl prey in Amorgos analysed in 39 pellets. Codes: a - Pied/Collared Flycatcher Ficedula hypoleuca/albicollis, $b$ - Woodchat Shrike Lanius senator, $c$ - Blackcap Sylvia atricapilla, $d$ - Chaffinch Fringilla coelebs, e - Blackbird Turdus merula, $f$ - Siskin Carduelis (Spinus) spinus, g - Chiffchaff Phylloscopus collybita, $h$ - gecko Mediodactylus kotschyi, $j$ - wall lizard Podarcis erhardii, $k$ - Copris hispanus, $m$ - Thorectes cf. bruelli, $n$ - Stonechat Saxicola (torquata) rubicola, $x$ - not identified. Localities \& dates: D - Dhri cave (1-23: 21. 5. 2015, 24-27: 21. 4. 2018, 28: 5. 4. 2019), AT - Agia Triada Shrine (6. 3. 2015, none found subsequently), A - Araklos gorge cave (22. 5. 2015), UL - unlabelled sample (labels lost, but UL1 \& 2 probably from D (30. 3. 2016, old pellets missed in 2015), 3 \& 4 from A (22. 5. 2015).

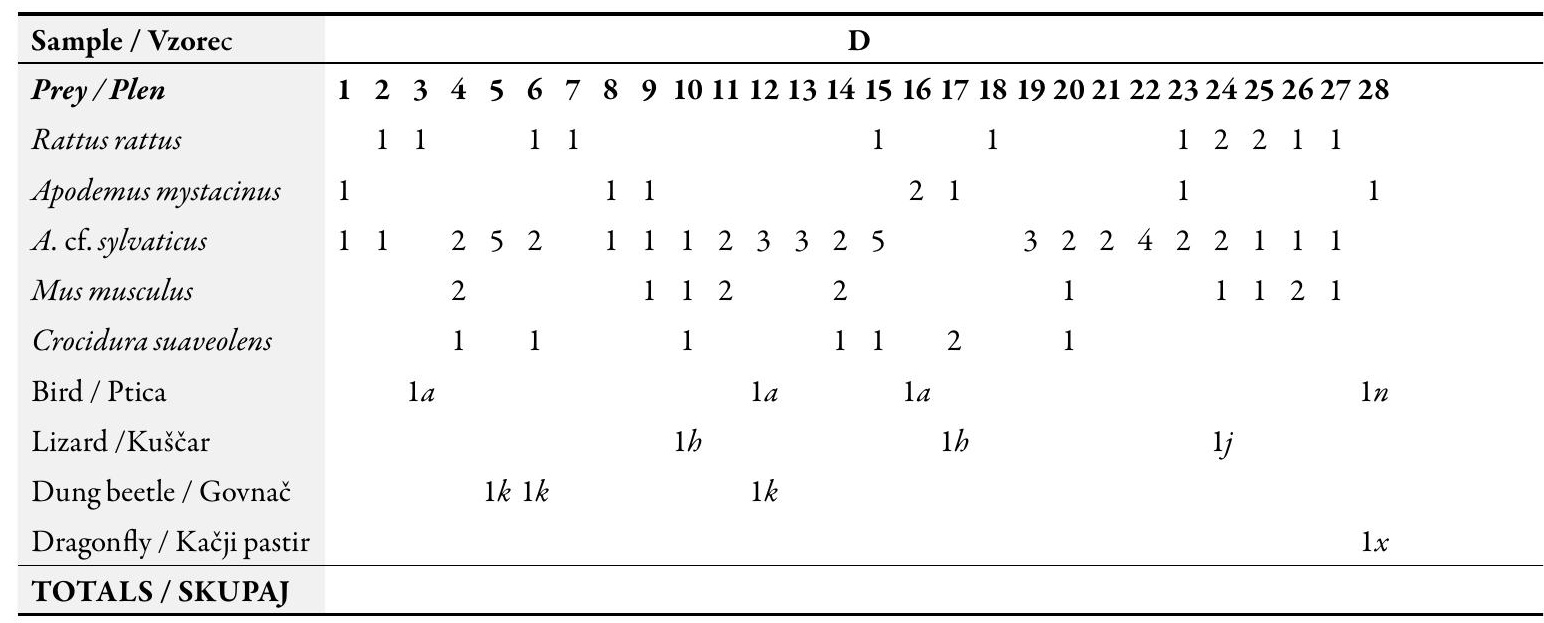


Tabela 1: Plen pegastih sov na otoku Amorgos, analiziran iz 39 izbljuvkov. Oznake: a - črnoglavi/belovrati muhar Ficedula hypoleuca/albicollis, $b$ - rjavoglavi srakoper Lanius senator, $c$ - črnoglavka Sylvia atricapilla, $d$ - ščinkavec Fringilla coelebs, e - kos Turdus merula, $f$ - čižek Carduelis (Spinus) spinus, $g$ - vrbji kovaček Phylloscopus collybita, $h$ - gekon Mediodactylus kotschyi, $j$ - Erhardova pozidna kuščarica Podarcis erhardii, $k$ - Copris hispanus, $m$ - Thorectes cf. bruelli, $n$ - prosnik Saxicola (torquata) rubicola, $x$ - ni določeno. Lokacije \& datumi: D - jama Dhri (1-23: 21. 5. 2015, 24-27: 21. 4. 2018, 28: 5. 4. 2019), AT - svetišče Agia Triada (6. 3. 2015, brez novejših najdb), A - jama v soteski Araklos (22. 5. 2015), UL - neoznačeni vzorci (oznake izgubljene, UL1 in 2 najverjetneje z lokalitete D (30. 3. 2016, stari izbljuvki spregledani v letu 2015), 3 \& 4 z lokalitete A (22. 5. 2015).

\begin{tabular}{|c|c|c|c|c|c|c|c|c|c|c|c|c|}
\hline \multirow[b]{2}{*}{ Total:D } & \multicolumn{6}{|c|}{ AT } & $\mathbf{A}$ & \multicolumn{4}{|c|}{ UL } & \multirow[b]{2}{*}{ Grand Total/Skupaj } \\
\hline & 1 & 2 & 3 & 4 & 5 & 6 & 1 & 1 & 2 & 3 & 4 & \\
\hline $13-13 \%(14)$ & & 1 & 1 & & & & & & & & & $15-12 \%$ \\
\hline $8-8 \%(8.5)$ & & & & & & & & 1 & 1 & & & $10-8 \%$ \\
\hline $47-47 \%(50)$ & & & & 1 & 2 & 1 & 1 & 2 & 3 & & 1 & $58-46 \%$ \\
\hline 14-14\% (15) & & 1 & & & & & & & & & & $15-12 \%$ \\
\hline $8-8 \%(8.5)$ & & & & & & & & & 2 & & & $10-8 \%$ \\
\hline $4-4 \%(4)$ & $1 b$ & & & $1 c$ & & & $2 d e$ & & & $3 d f g$ & & $11-9 \%$ \\
\hline $3-3 \%-$ & & & & & & & & & & & & $3-2.5 \%$ \\
\hline $3-3 \%-$ & $1 x$ & $1 m$ & & & & & & & & & & $5-4 \%$ \\
\hline 1-1\% & & & & & & & & & & & & $1-0.8 \%$ \\
\hline $101(94)$ & & & & & & & & & & & & $125(119)$ \\
\hline
\end{tabular}

Table 2: Numbers of rodent and shrew jaws, and minimum total of bird humeri (from Table 5) recovered loose from the floor of Dhri Cave ( $\mathrm{L}$ - left, $\mathrm{R}$ - right jaws). Minimum number of mammal individuals indicated by the higher figure for left or right in italics, numbers then used in Table 3. Minimum bird numbers as shown in Table 5.The lizard is Podarcis erhardii.

Tabela 2: Število čeljusti glodalcev in rovk ter minimalno število nadlahtnic ptic (iz tabele 5), pridobljenih iz tal jame Dhri ( $\mathrm{L}$ - leva, R - desna čeljust). Minimalno število osebkov sesalcev (višja vrednost za levo ali desno čeljust) je zapisano ležeče, vrednost pa je nato uporabljena v tabeli 3. Minimalno število ptic, kot jih prikazuje tabela 5. Kuščar je Podarcis erhardii.

\begin{tabular}{|c|c|c|c|c|c|c|c|c|c|c|c|c|}
\hline \multirow{2}{*}{$\frac{\text { Species / Vrsta }}{\text { Date / Datum }}$} & \multicolumn{2}{|c|}{$\begin{array}{c}\sqrt{2} \\
2 \\
2 \\
3\end{array}$} & \multicolumn{2}{|c|}{ 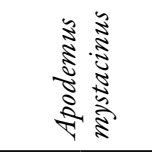 } & \multicolumn{2}{|c|}{ पू } & \multicolumn{2}{|c|}{$\begin{array}{r}\frac{\pi}{3} \\
3 \\
\frac{2}{3} \\
\frac{3}{3} \\
2\end{array}$} & \multicolumn{2}{|c|}{ 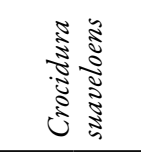 } & \multirow{2}{*}{ 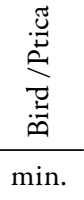 } & \multirow{2}{*}{ 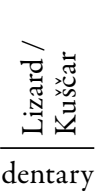 } \\
\hline & $\mathrm{L}$ & $\mathrm{R}$ & $\mathrm{L}$ & $\mathrm{R}$ & $\mathrm{L}$ & $\mathrm{R}$ & $\mathrm{L}$ & $\mathrm{R}$ & $\mathrm{L}$ & $\mathrm{R}$ & & \\
\hline May 2015 & 51 & 50 & 6 & 6 & 18 & 19 & & & 7 & 5 & & \\
\hline March 2016 & 63 & 60 & 10 & 13 & 30 & 29 & & 2 & 12 & 4 & & \\
\hline October 2017 & 12 & 15 & 2 & 1 & 5 & 7 & 1 & 1 & 4 & 3 & & \\
\hline April 2018 & 42 & 49 & 11 & 9 & 38 & 30 & 4 & 3 & 16 & 21 & & 1 \\
\hline April 2019 & 17 & 12 & 6 & 2 & 10 & 10 & 3 & 3 & 1 & 3 & & 1 \\
\hline $\begin{array}{l}\text { TOTALS (459) / } \\
\text { SKUPAJ (459) }\end{array}$ & 185 & 186 & 35 & 31 & 101 & 95 & 8 & 9 & 40 & 37 & 86 & 2 \\
\hline$\%$ (rounded) & & 40.5 & 7.5 & & 22 & & & 2 & 9 & & 19 & \\
\hline
\end{tabular}


A. S. Cheke, J. P. Hume: The diet, and pellet residue taphonomy, of Barn Owls Tyto alba on a Greek island reveals an exceptional diversity of avian prey

or rarely catch are summer visitors Olivaceous Warbler Hippolais (Iduna) pallida, and wheatears Oenanthe spp., passage migrants Common Redstart Phoenicurusphoenicurus, Wood Warbler Phylloscopus sibilatrix and Tree Pipit Anthus trivialis, and winter visitors Meadow Pipit Anthus pratensis, Pied Wagtail Motacilla alba and Corn Bunting Emberiza calandra. The preponderance of Chaffinches may be due to there being a large winter roost near cave D (ASC \& REA unpublished data); likewise the frequently predated Blackcaps Sylvia atricapilla are very common on migration, and frequent as winter visitors, sometimes also aggregating in the vicinity of the owl roosts (CHEKE \& AsHCROFT 2016).

There have been several other published studies of Barn Owl diet in Greece, only two of which involved a small island, Antikythira (Alivizatos et al. 2005) and Milos (Alivizatos \& Andriopoulos 2016). Antikythira, off the southern Peloponnese, famous for quantity and variety of migratory birds (e.g. Dimaki et al. 2006), is less than half the size of Amorgos and has only two species of rodent (Rattus rattus \& Mus musculus; ibid.), yet only about 9-10 species of birds were found in Barn Owl diet (Alivizatos et al. 2005, 2+ species not identified; Table 6), though the presence of a rail Porzana sp., Barn Swallow Hirundo rustica, flycatchers Ficedula sp. and shrikes Lanius sp. suggests migrants were targeted, though the owls also took a young Chukar partridge Alectoris chukar and even a Scops Owl Otus scops. Milos, at $151 \mathrm{~km}^{2}$, is a bit larger than Amorgos, and here also the owls at two sites took some larger species than on Amorgos (fledgling kestrel, 2 species of pigeon; Table 6), and also targetted resident species more than in Amorgos, though migrants were captured in autumn (Alivizatos \& ANDRIOpOulos 2016); bird numbers, at $6 \%$ of mammals, were lower than in Amorgos. The study was said to be ongoing, although no further data have been published.

Of mainland Greek sites, birds averaged 4\% by number and less in biomass, but were $39.6 \%$ (winter) to $43.4 \%$ (summer) of diet as biomass at Mitrikou, a wetland site in northeastern Greece (Goutner \& Alivizatos 2003). Although only $11-13 \%$ in number - the birds were not identified to species but the number/biomass ratio suggests largish species, probably non-passerines (waders?) were targetted at this site. ОвUCH \& BENDA (2009) reported 14 bird species total from two sites in the Peloponnese (Greek mainland) and 15 from five sites in Crete (Table 6), while Alivizatos et al. (2005) recorded only 2-7 species each in six mainland sites, and Bontzorlos et al. (2005) only two species in three sites, though up to $9 \%$ of items in winter at one of them.

Table 3: Chi-square test comparing proportions of prey species in loose bones and pellets from the Dhri Cave, testing an expectation of equal proportions (calculated 'expected' figures in italics). $\chi^{2}=79.6, \mathrm{df}=5, \mathrm{p}<<0.0001$. The individual $\chi^{2}$ in bold indicate major departures from the expected result that both loose bones and pellets would have the same proportions of prey. For loose bones the counts are for the most frequent bones by taxa: mammal jaws and bird humeri.

Tabela 3: Hi-kvadrat primerjave razmerja vrst plena v izbljuvkih in njihovih ostankih (posamezne kosti) iz jame Dhri, test pričakovanih enakomernih razmerij (izračunane pričakovane vrednosti v ležeči pisavi). $\chi^{2}=79.6, \mathrm{df}=5$, $p<<0.0001$. Posamezen $\chi^{2} v$ krepki pisavi prikazuje velike odklone od pričakovanja, da so razmerja vrst plena $v$ izbljuvkih in njihovih ostankih (posamezne kosti) enaka. Pri posameznih kosteh so podane vrednosti za najpogostejše kosti iz taksona: čeljusti sesalcev in nadlahtnice ptic.

\begin{tabular}{lrrrrrrr}
\hline Taxa / Takson & $\begin{array}{l}\text { Rattus } \\
\text { rattus }\end{array}$ & $\begin{array}{l}\text { Apodemus } \\
\text { mystacinus }\end{array}$ & $\begin{array}{l}\text { Apodemus cf. } \\
\text { sylvaticus }\end{array}$ & $\begin{array}{l}\text { Mus } \\
\text { musculus }\end{array}$ & $\begin{array}{l}\text { Crocidura } \\
\text { suaveolens }\end{array}$ & $\begin{array}{l}\text { Birds / } \\
\text { Ptice }\end{array}$ & $\begin{array}{l}\text { Totals / } \\
\text { Skupaj }\end{array}$ \\
\hline Loose bones / & 186 & 35 & 101 & 9 & 40 & 86 & \\
posamezne kosti & 165.1 & 35.7 & 122.8 & 19.1 & 39.8 & 74.6 & 457 \\
& $(2.67)$ & $(0.01)$ & $(3.87)$ & $(\mathbf{5 . 3 4})$ & $(0.00)$ & $(1.74)$ & \\
Pellets / & 13 & 8 & 47 & 14 & 8 & 4 & \\
Izbljuvki & 33.9 & 7.3 & 25.2 & 3.9 & 8.2 & 15.4 & $\mathbf{9 4}$ \\
& $(\mathbf{1 2 . 8 8})$ & $(0.07)$ & $(\mathbf{1 8 . 8 6})$ & $(\mathbf{2 6 . 1 6})$ & $(0.00)$ & $(\mathbf{8 . 4 3})$ & \\
\hline Totals / Skupaj & $\mathbf{1 9 9}$ & $\mathbf{4 3}$ & $\mathbf{1 4 8}$ & $\mathbf{2 3}$ & $\mathbf{4 8}$ & $\mathbf{9 0}$ & $\mathbf{5 5 1}$ \\
\hline
\end{tabular}


The only report we have found that appears comparable to the Amorgos situation is from the Balearic islands at the other end of the Mediterranean. Guerra et al. (2014) looked at the diet of Barn Owls on Formentera and islets adjacent to neighbouring Eivissa (Ibiza), finding a rich combined haul of nearly 30 species, mostly migrants: individually, more than 21 on the small islet of s'Espalmador and more than 16 combining two sites on Formentera (Table 6; numbers include some species identified only to genus). The species range here was wider than on Amorgos, embracing Storm-petrel Hydrobates pelagicus (local breed- ing seabird), Common Quail, waders Charadrius alexandrinus, Calidris ferruginea and Tringa sp., a marsh tern Chlidonias sp. and Common Bee-eater Merops apiaster, reflecting in part the greater range of habitats available - Amorgos has only tiny token wetlands. Comparative results from an inland site in Ibiza are added from Sommer et al. (2005) in Table 6. As in Greece, on these islands the bulk of the prey was rodents.

We were unable to study seasonal variation in catch, but as with Alivizatos \& ANDriopoulos on Milos, Bosé \& Guidali (2001) in north Italy found an increase in birds taken in summer/

Table 4: Numbers of loose complete bird bones on Dhri cave floor, by collection date [excluding radiuses or scapulas as too few to be worth listing], compared with Denys et al.'s percentages (2017). Note that the collecting dates in 2015-2018 are sampling from the same initial bone 'population' as there was no new input in the intervals; the return of owls in 2018 may have added a few bones before the 2019 collection. Humerus heads, although identifiable, excluded to retain comparability with other bones. The low figures in 2019 reflect diminishing returns as the site is worked out. Abbreviations: CMC - carpometacarpus, TbT - Tibiotarsus, TMT - Tarsometatarsus.

Tabela 4: Število posameznih celih kosti ptic na tleh jame Dhri, glede na čas zbiranja [brez koželjnic in lopatic, ki jih je v vzorcu premalo] in v primerjavi z odstotki, navedenimi v Denys et al. (2017). Kosti, nabrane v obdobju 2015-2018, predstavljajo vzorec iz istega začetnega vzorca, saj v obdobju ni bilo najdenega novega, svežega materiala. Vrnitev sov v letu 2018 je prispevalo nekaj novih kosti pred vzorčenjem v letu 2019. Glave nadlahtnice, čeprav določene, so bile izločene zaradi zagotavljanja ustreznosti z drugimi kostmi. Majhne vrednosti v letu 2019 kažejo na zmanjševanje kosti v začetnem vzorcu. Okrajšave: CMC - karpometakarpus, TbT - golenično-nartna kost, TMT - Tarzusmetatarzus.

\begin{tabular}{|c|c|c|c|c|c|c|c|c|}
\hline \multirow[b]{2}{*}{ Bone / kost } & \multicolumn{5}{|c|}{ Date / Datum } & \multirow[b]{2}{*}{$\begin{array}{r}\text { TOTALS/ } \\
\text { SKUPAJ } \\
\end{array}$} & \multirow[b]{2}{*}{$\begin{array}{l}\text { \% post-cranial/ } \\
\% \text { brez lobanje }\end{array}$} & \multirow[b]{2}{*}{$\begin{array}{l}\text { Denys et } \\
\text { al }(2017)\end{array}$} \\
\hline & $\begin{array}{l}\text { May } \\
2015\end{array}$ & $\begin{array}{r}\text { March } \\
2016\end{array}$ & $\begin{array}{r}\text { October } \\
2017\end{array}$ & $\begin{array}{l}\text { April } \\
2018\end{array}$ & $\begin{array}{c}\text { April } \\
2019\end{array}$ & & & \\
\hline coracoid / krokarnica & 3 & 11 & 7 & 13 & 2 & 36 & 9.2 & 14.3 \\
\hline humerus / nadlahtnica & 34 & 39 & 17 & 26 & 11 & 127 & 32.6 & 10.7 \\
\hline ulna / komolčnica & 11 & 29 & 14 & 23 & 10 & 87 & 22.4 & 10.7 \\
\hline CMC & 5 & 12 & 4 & 8 & 3 & 32 & 8.2 & 8.9 \\
\hline femur / stegnenica & 11 & 17 & 10 & 11 & 1 & 50 & 12.9 & 19.6 \\
\hline $\mathrm{TbT}$ & 6 & 7 & 4 & 2 & - & 19 & 4.9 & 17.9 \\
\hline TMT & 13 & 6 & 7 & 8 & 4 & 38 & 9.8 & 17.9 \\
\hline $\begin{array}{l}\text { Total post-cranial / } \\
\text { skupaj brez lobanje }\end{array}$ & & & & & & 389 & & 56 \\
\hline $\begin{array}{l}\text { skull (cranium+bill) / } \\
\text { skupaj (lobanja+kljun) }\end{array}$ & 1 & 1 & $\begin{array}{l}1 \text { (partial } \\
\text { / delna) }\end{array}$ & & 2 & 5 & & \\
\hline $\begin{array}{l}\text { cranium (no bill) / } \\
\text { lobanja (brez kljuna) }\end{array}$ & 1 & & & & & 1 & & \\
\hline $\begin{array}{l}\text { upper mandible / } \\
\text { zgornja čeljust }\end{array}$ & 4 & 9 & 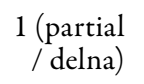 & & 2 & 20 & & \\
\hline $\begin{array}{l}\text { lower mandible / } \\
\text { spodnja čeljust }\end{array}$ & 5 & 7 & 3 & & & 15 & & \\
\hline
\end{tabular}


A. S. Cheke, J. P. Hume: The diet, and pellet residue taphonomy, of Barn Owls Tyto alba on a Greek island reveals an exceptional diversity of avian prey

Table 5: Avian prey of Barn Owls \& their status in Amorgos, from loose bones on floor of Dhri cave (site D), listed by size of humerus. Conventions \& Codes: $\mathrm{n}[\mathrm{x} / \mathrm{y}]-$ total [left/right] $+\mathrm{h}$ [head of humerus only]; under status: PM passage migrant, $\mathrm{R}$ - resident, SV - summer visitor, WV - winter visitor, qualified by a = abundant, $\mathrm{c}-\mathrm{common}, \mathrm{f}-$ frequent/fairly common, $\mathrm{s}$ - scarce, $r$ - rare. > refers across to comment column. Weight data from SNOW \& PERRINS (1998), except, due to an obvious printing error, Greenfinch from PerRINs (1987); status data: ASC, REA \& Apostolos Cristopoulos (pers. obs. 2007-19 in CHEKE et al. 2020). '+X' in bold in column 7 indicates additional specimens in pellets, not included in total.

\begin{tabular}{|c|c|c|c|c|c|}
\hline $\begin{array}{c}\text { Humerus } \\
\text { sample Ref./ } \\
\text { Oznaka vzorca } \\
\text { nadlahtnice }\end{array}$ & $\begin{array}{c}\text { Size of samples } \\
(\mathrm{mm}) / \\
\text { Velikost vzorca } \\
(\mathrm{v} \mathrm{mm})\end{array}$ & $\begin{array}{c}\text { Weight } \\
\text { range }(\mathrm{g}) / \\
\text { razpon teže }(\mathrm{g})\end{array}$ & English name / Angleško ime & Scientific name / Znanstveno ime & Status \\
\hline $\mathrm{lb}$ & 12 & $6-10$ & Chiffchaff & Phylloscopus collybita & $\mathrm{PMc}, \mathrm{WVc}$ \\
\hline 1c & 12.5 & $7-12$ & Willow Warbler & P.trochilus & PMc \\
\hline $25,25 a$ & 13 & $8-13$ & Subalpine Warbler & Sylvia cantillans & $S V_{c}$ \\
\hline 33 & 13.5 & $9-15$ & Sedge Warbler & Acrocephalus schoenobaenus & PMs \\
\hline 24 & 13.5 & $10-15$ & Sardinian Warbler & Sylvia melanocephala & $\mathrm{Ra}$ \\
\hline 31 & $14-14.5$ & $11-18$ & Siskin & Carduelis (Spinus) spinus & $\mathrm{WV}^{*}$ \\
\hline 32 & $14.5-15$ & $13-18$ & Whitethroat & Sylvia communis & $\mathrm{PMf}, \mathrm{SVr}$ \\
\hline $2,2 b$ & 15 & $10-16$ & Pied / Collared Flycatcher & Ficedula hypoleuca / albicollis & both PMc \\
\hline $20,20 \mathrm{a}$ & 15 & $13-17$ & Stonechat & Saxicola (torquata) rubicola & Rs, WVf \\
\hline 13 & 15 & $16-22$ & House Martin & Delichon urbicum & $\mathrm{PMa}$ \\
\hline 4 & 16 & $14-19$ & Goldfinch & Carduelis carduelis & $\mathrm{Rs}, \mathrm{WVf}$ \\
\hline 14 & 16 & $11-14$ & Serin & Serinus serinus & WVs \\
\hline 28 & 16 & $14-20$ & Spotted Flycatcher & Muscicapa striata & $\mathrm{PMa}$ \\
\hline 3abcefgh & $16-17$ & $14-19$ & Whinchat & Saxicola rubetra & $\mathrm{PMc}$ \\
\hline 230 & 16.5 & & Robin & Erithacus rubecula & WVc \\
\hline 5,5abcde & $16-18$ & $16-25$ & Blackcap / Garden Warbler & Sylvia atricapilla / borin & $\mathrm{PMa}, \mathrm{WVf} / \mathrm{PMr}$ \\
\hline 30 & {$[15-17]$} & $16-25$ & Dunnock & Prunella modularis & WVr \\
\hline $4 a$ & 17 & $15-22$ & Linnet & Carduelis (Linaria) cannabina & $\mathrm{Rc}, \mathrm{WV} \mathrm{c}$ \\
\hline $7,7 \mathrm{a}$ & 18 & $13-19$ & Black Redstart & Phoenicurus ochruros & WVc \\
\hline 8 & 18 & $24-38$ & House Sparrow & Passer domesticus & $\mathrm{Ra}$ \\
\hline 22 & 18 & $20-25$ & Ortolan / Cretzchmar's Bunting & Emberiza hortulana / caesia & both PMs \\
\hline $26,26 a$ & 18 & $17-24$ & Nightingale & Luscinia megarhynchos & SVf \\
\hline $6,6 a$ & $18-19$ & $25-34$ & Greenfinch & Carduelis (Chloris) chloris & WVs \\
\hline 9,9abcdef & $18-20.5$ & $18-29$ & Chaffinch / Brambling & Fringilla coelebs / montifringilla & $\mathrm{Rs}, \mathrm{WVa} / \mathrm{WV} \mathrm{s}$ \\
\hline 10 & 18.5 & $16-25$ & Orphean Warbler & Sylvia hortensis (S. crassirostris) & SVf \\
\hline 21 & 19 & $14-23$ & cf. Olive-tree Warbler & Hippolais cf. olivetorum & $\mathrm{PMr}$ \\
\hline 29 & $19+$ & $35-50$ & Crossbill & Loxia curvirostra & $\mathrm{WVr}$ \\
\hline $11,11 a b c$ & 20 & $25-35$ & Red-backed Shrike & Lanius collurio & PMc \\
\hline $12,12 \mathrm{a}$ & $22-22.5$ & $30-40$ & Woodchat Shrike & L. senator & SVf \\
\hline $27,27 \mathrm{a}$ & 24 & $30-45$ & Wryneck & Jynx torquilla & PMs \\
\hline 18 & 24 & $46-70$ & Hawfinch & Coccothraustes coccothraustes & WVs \\
\hline 31 & 26 & $37-55$ & Crested Lark & Galerida cristata & $\mathrm{Rc}$ \\
\hline 16 & 26 & $65-100$ & Song Thrush & Turdusphilomelos & WVc \\
\hline 17 & $27-28$ & $50-90$ & Starling & Sturnus vulgaris & WVs \\
\hline $15,15 \mathrm{abc}$ & $29-30$ & $80-125$ & Blackbird & Turdus merula & WVc \\
\hline 19 & 31 & $56-79$ & Golden Oriole & Oriolus oriolus & PMc \\
\hline
\end{tabular}

\section{Total humeri / Skupaj nadlhatnice}

Additional species identified from other bones / Dodatne vrste, določene na podlagi drugih kosti:

\begin{tabular}{lllll}
\hline 2018 ulnas & $26-50$ & Skylark & Alauda arvensis & WVf \\
\hline TBT31 & $18-29$ & Tree Pipit & Anthus trivialis & PMc \\
\hline Bill 6 & $22-36$ & Spanish Sparrow & Passer hispaniolensis & PMf
\end{tabular}


Tabela 5: Ptice kot plen pegaste sove in njihov status na otoku Amorgos iz vzorca posameznih kosti na tleh jame Dhri (lokaliteta D), navedene po velikosti nadlahtnice. Oznake: $\mathrm{n}[\mathrm{x} / \mathrm{y}]$-skupaj [leva/desna] + h[le glava nadlahtnice], PM - selivka, R - stalnica, SV - polenta obiskovalka, WV - prezimovalka, a - zelo pogosta, c - pogosta, $f$ - manj pogosta, s - redka, r - zelo redka. Podatki o teži iz Snow \& Perins (1998), le zelenec zaradi napake v tisku iz PERRIS (1987). Podatki o status vrste: ASC, REA in Apostolos Cristopoulos (osebno opazovanje 2007-2019 in CHEKE in sod. v 2020). +X krepko označuje dodatne osebke v izbljuvkih, ki niso vključeni v seštevek.

No. whole humeri $[\mathrm{L} / \mathrm{R}]$

Min. No. of or heads only $h[\mathrm{~L} / \mathrm{R}] /$

birds / Min. Št. celih ali samo glav Additional comments [additional bones noted where identified - mostly only from larger species] /

št.ptic nadlahtnic Dodatni komentarji

\begin{tabular}{|c|c|c|}
\hline $1+1>$ & $1>[1 /-]$ & confirmed against pellet sample UL3 \& NHM collections \\
\hline 2 & $2[-/ 2]$ & consistent differences from Chiffchaff \\
\hline 2 & $4[2 / 2]$ & \\
\hline 1 & $1[-/ 1]$ & \\
\hline 1 & $1[1 /-]$ & \\
\hline $0+1$ & $2[1 / 1]$ & [from pellet UL3] *irruptive; rare visitor, but common when arrives \\
\hline 2 & $2[1 / 1]+h[-/ 1]$ & \\
\hline $4+3>$ & $5[3 / 2]+h[1 /-]$ & not separable; both common; close to Stonechat; F.semitorquata also possible] [also pellets D3, D12, D16] \\
\hline $3+1>$ & $2[2 /-]+h[1 /-]$ & [>also pellet $\mathrm{D} 28]$ \\
\hline 1 & $2[1 / 1]$ & \\
\hline 1 & $2[1 / 1]$ & \\
\hline 1 & $1[-/ 1]$ & \\
\hline 1 & $1[1 /-]$ & very close to Whinchat \& similar also to Redstart Phoenicurus phoenicurus \\
\hline 8 & $15[8 / 7]$ & close to Spotted Flycatcher \\
\hline 1 & $1[1 /-]$ & \\
\hline $11+1>$ & $15[5 / 10]+h[1 / 1]$ & not separable, but Garden Warbler is very scarce [>also pellet sample AT4] \\
\hline 1 & $h[1 /-]$ & head of bone only \\
\hline 1 & $2[1 / 1]$ & \\
\hline 2 & $3[2 / 1]$ & \\
\hline 2 & $2[1 / 1]+\mathrm{h}[-/ 1]$ & \\
\hline 2 & $2[2 /-]$ & not separable; both scarce \\
\hline 1 & $2[1 / 1]$ & \\
\hline 2 & $2[1 / 1]+\mathrm{h}[-/ 1]$ & \\
\hline $12+3>$ & $22[12 / 10]$ & not separable, but Brambling is scarce; [>also pellet samples A1, UL3, D-partial 2017] \\
\hline 1 & {$[1 /-]$} & \\
\hline 1 & $1[-/ 1]$ & $\begin{array}{l}\text { not confirmed to species as no comparative material available, but H.olivetorum is the only member of } \\
\text { the genus in the size range }\end{array}$ \\
\hline 1 & $1[-/ 1]$ & more robust than Greenfinch/sparrow \\
\hline 5 & $9[5 / 4]$ & also an ulna in floor samples \\
\hline $1+1>$ & $2[1 / 1]$ & also 2 ulnas in floor samples [>also pellet AT1] \\
\hline 2 & $2[1 / 1]+\mathrm{h}[1 /-]$ & similar to shrike/lark \\
\hline 1> & $2[1 / 1]-$ & also 2 skulls \& coracoids in floor samples \\
\hline 1 & $1[1 /-]$ & also ulnas \& upper mandible in floor samples \\
\hline 2 & $3[1 / 2]$ & also most other long-bones in floor samples \\
\hline 2 & $2[1 / 1]+h[1 /-]$ & \\
\hline $5+1>$ & $6[5 / 1]+\mathrm{h}[-/ 2]$ & also most other long-bones in floor samples [>also pellet sample Al] \\
\hline 1 & $1[1 /-]+h[-/ 1]$ & also 2 ulnas, a coracoid \& a carpometacarpus in floor samples \\
\hline
\end{tabular}

\section{$86+12$}

1

$1+$

1 ulna

tibiotarsus

upper mandible 
A. S. Cheke, J. P. Hume: The diet, and pellet residue taphonomy, of Barn Owls Tyto alba on a Greek island reveals an exceptional diversity of avian prey

Table 6. Avian prey on Mediterranean islands compared (see text for references). Crete is included to compare a large island on the same migration route as Antikythera and the Cyclades (Milos, Amorgos). Code: dno - does not occur (on specified island). NB: 2 more species in the Ibiza islands were unidentified - these could overlap with identified species (different bones?) or could add a further 2+ species to the combined list. Equally in Amorgos there are probably unidentified further species amongst harder-to-identify bones not checked in detail (ulna, femur etc). References: A - this paper, B - Obuch \& Benda 2009, C - Alivizatos \& Andriopoulos 2016, D - Guerra et al. (2014), E - Sommer et al. (2005). Notes: 1 - Lanius sp., 2 - Turdus/Sturnus, 3 - Sylvia sp., 4 - Ficedula sp. in Antikythera, as 'Muscicapidae small size' in Ibiza, 5 - Turdus sp. (large size), 6 - Emberiza sp. (uncertain), 7 - At San Carlos there were also numerous unidentified bird remains, but they were not sorted by bone type, 8 - fledgling, 9 - Phylloscopus sp., 10 - 28 is combined total for s'Espalmador \& Formentera.

Tabela 6: Primerjava ptic kot plena na sredozemskih otokih. Kreta je vključena kot primerjava velikega otoka na isti selitveni poti kot otoki Antikitera in Kikladi (Milos, Amorgos). Oznake: dno - vrsta se ne pojavlja. Dve vrsti ptic na Ibizi nista bili določeni, kar se lahko prekriva z že določenimi vrstami (različne kosti) ali pa predstavljata dve dodatni vrsti. Podobno velja za Amorgos, kjer bi med težko določljivi kostmi verjetno našli še kakšno dodatno vrsto. Viri: A - ta raziskava, B - Obuch \& Benda (2009), C - Alivizatos \& Andriopoulos (2016), D - Guerra et al. (2014), E Sommer et al. (2005). Opombe: 1 - Lanius sp., 2 - Turdus/Sturnus sp., 3 - Sylvia sp., 4 - Ficedula sp. na Antikiteri in majhna Muscicapidae na Ibizi, 5 - večja vrsta Turdus sp., 6 - Emberiza sp. (negotovo); 7 - v San Carlosu so bili številni nedoločeni ostanki ptic, ki pa niso bili razvrščeni po tipu kosti, 8 - mladič., 9 - Phylloscopus sp., 10 - 28 je skupno število vrst v Espalmador \& Formentera.

\begin{tabular}{|c|c|c|c|c|c|c|c|c|}
\hline Species / Vrsta & Lokaliteta & 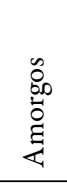 & $\frac{\pi}{\stackrel{\pi}{ \pm}}$ & $\stackrel{0}{3}$ & 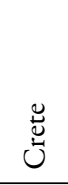 & 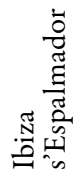 & 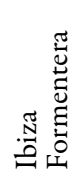 & 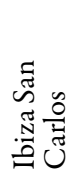 \\
\hline & Reference / Vir & A & B & $\mathrm{C}$ & B & $\mathrm{D}$ & $\mathrm{D}$ & $\mathrm{E}$ \\
\hline Storm-petrel & Hydrobates pelagicus & dno & dno & dno & dno & * & & \\
\hline Common Kestrel & Falco tinnununculus & & & ${ }^{*} 8$ & & & & \\
\hline Chukar Partridge & Alectoris chukar, chick & & $*$ & & & & & \\
\hline Common Quail & Coturnix coturnix & & & & & $*$ & & \\
\hline Rail sp. & Porzanasp. & dno & $*$ & & & & & \\
\hline Kentish Plover & Charadrius alexandrinus & dno & & & & * & & \\
\hline Scops Owl & Otus scops & & $*$ & & & & & \\
\hline Curlew sandpiper & Calidris ferruginea & dno & & & & $*$ & & \\
\hline 'shank' & Tringa sp. & & & & & $*$ & & \\
\hline marsh tern & Chlidonias sp. & dno & & & & $*$ & & \\
\hline Rock Dove & Columba livia & & & $*$ & & & & \\
\hline Turtle-dove & Streptopelia turtur & & & & * & & & \\
\hline Collared-dove & Streptopelia decaocto & & & * & & & & \\
\hline Bee-eater & Merops apiaster & & & & & & $*$ & \\
\hline Wryneck & Jynx torquilla & * & & & & * & * & \\
\hline Crested Lark & Galerida cristata & $*$ & & $*$ & $*$ & & & \\
\hline Skylark & Alauda arvensis & $*$ & & & & & $*$ & \\
\hline Short-toed Lark & Calandrella brachdacryla & & & & & $*$ & $*$ & \\
\hline Barn Swallow & Hirundo rustica & & * & & & & * & \\
\hline House Martin & Delichon urbica & $*$ & & & & & & \\
\hline Tree Pipit & Anthus trivialis & $*$ & & & & & & \\
\hline
\end{tabular}




\begin{tabular}{|c|c|c|c|c|c|c|c|c|}
\hline Species / Vrsta & Lokaliteta & 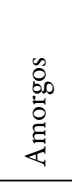 & 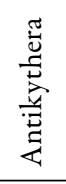 & $\stackrel{\tilde{0}}{\Xi}$ & 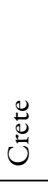 & 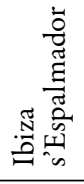 & 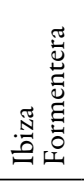 & 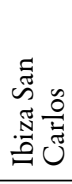 \\
\hline & Reference / Vir & A & B & $\mathrm{C}$ & $\mathrm{B}$ & $\mathrm{D}$ & $\mathrm{D}$ & $\mathrm{E}$ \\
\hline Meadow Pipit & Anthus pratensis & & & & & * & & \\
\hline Wren & Troglodytes troglodytes & & & & & * & & \\
\hline Woodchat Shrike & Lanius senator & * & $\left({ }^{*} 1\right)$ & $\left({ }^{*} 1\right)$ & & & * & \\
\hline Red-backed Shrike & Lanius collurio & * & $\left({ }^{*} 1\right)$ & $\left({ }^{*} 1\right)$ & & * & & \\
\hline Golden Oriole & Oriolus oriolus & * & & & & & & \\
\hline Starling & Sturnus vulgaris & * & & & & *2 & & \\
\hline Great Tit & Parus major & dno & & dno & $*$ & & & \\
\hline Dunnock & Prunella modularis & * & & & & & & \\
\hline Blackcap / Garden Warbler & Sylvia atricapilla / borin & * & & ${ }^{*} 3$ & *3 & * & *3 & *3 \\
\hline Whitethroat & Sylvia communis & * & & & & & & \\
\hline Subalpine Warbler & Sylvia cantillans & $*$ & & & & & & \\
\hline Orphean Warbler & Sylvia hortensis (S. crassirostris) & * & & & & & & \\
\hline Sardinian Warbler & Sylvia melanocephala & * & & * & & & & \\
\hline Sedge Warbler & Acrocephalus schoenobaenus & * & & & & & & \\
\hline cf. Olive-tree Warbler & Hippolais olivetorum & * & & & & dno & dno & dno \\
\hline Chiffchaff & Phylloscopus collybita & * & & * & & & $\left({ }^{*} 9\right)$ & \\
\hline Willow Warbler & Phylloscopus trochilus & $*$ & & ${ }^{*} 9$ & & & $\left(*^{*} 9\right)$ & \\
\hline Gold- / Firecrest & Regulussp. & & & & $*$ & & & \\
\hline Pied / Collared Flycatcher & Ficedula hypoleuca / albicollis & * & $* 4$ & & & * & * & \\
\hline Spotted Flycatcher & Muscicapa striata & * & & * & & & & \\
\hline Whinchat & Saxicola rubetra & $*$ & & & & & & \\
\hline Stonechat & Saxicola torquata (S.rubicola) & * & & & & & & \\
\hline Wheatear sp. & Oenanthe sp. & & & & $*$ & & & \\
\hline Black Redstart & Phoenicurus ochrurus & $*$ & & & * & * & * & \\
\hline Robin & Erithacus rubecula & * & & * & * & * & * & * \\
\hline Nightingale & Luscinia megarhynchos & * & & & & & & \\
\hline Blue Rock-thrush & Monticola solitarius & & & * & & & & \\
\hline Blackbird & Turdus merula & * & & & * & $(* 5)$ & * & \\
\hline Songthrush & Turdus philomelos & * & & * & & & & \\
\hline House Sparrow & Passer domesticus & * & & * & * & * & * & * \\
\hline Spanish Sparrow & Passer hispaniolensis & * & & & & & & \\
\hline Tree Sparrow & Passer montanus & dno & & dno & * & & & \\
\hline Chaffinch / Brambling & Fringilla coelebs / montifringilla & $*$ & & & * & * & & * \\
\hline
\end{tabular}


A. S. Cheke, J. P. Hume: The diet, and pellet residue taphonomy, of Barn Owls Tyto alba on a Greek island reveals an exceptional diversity of avian prey

Continuation of Table 6 / Nadaljevanje tabele 6

\begin{tabular}{|c|c|c|c|c|c|c|c|c|}
\hline Species / Vrsta & Lokaliteta & 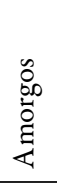 & 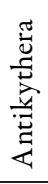 & $\stackrel{0}{\Xi}$ & 苞 & 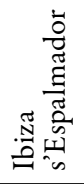 & 芯 & 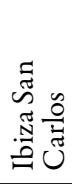 \\
\hline & Reference / Vir & A & $\mathrm{B}$ & $\mathrm{C}$ & $\mathrm{B}$ & $\mathrm{D}$ & $\mathrm{D}$ & E \\
\hline Hawfinch & Coccothraustes coccothraustes & * & & & & & & \\
\hline Crossbill & Loxia curvirostra & * & & & & & & \\
\hline Serin & Serinus serinus & * & & & & & & * \\
\hline Greenfinch & Carduelis (Chloris) chloris & * & & & * & * & & * \\
\hline Goldfinch & Carduelis carduelis & * & & & & & * & * \\
\hline Linnet & Carduelis (Linaria) cannabina & * & & & * & * & * & \\
\hline Siskin & Carduelis (Spinus) spinus & * & & & & & & \\
\hline Corn Bunting & Emberiza calandra & & $*$ & & * & & & \\
\hline $\begin{array}{l}\text { Ortolan / Cretzschmar's } \\
\text { Bunting }\end{array}$ & Emberiza hortulana / caesia & * & & & & & *6 & \\
\hline No. of species / Št. vrst & & 39 & 7 & 14 & 15 & $\begin{array}{c}21 \\
>28 \\
<(10)\end{array}$ & 16 & $7(7)$ \\
\hline
\end{tabular}

autumn. However more striking were the differences between two pairs (roosts \& nest sites) only a few kilometres apart in agricultural habitat. One caught only $3.7 \%$ birds, the other $16.5 \%$; in both case sparrows Passer spp. (mostly P. domesticus) were the major component (54-58\%), but other species were not fully identified so the diversity is not known, though a total of 11 species are mentioned. Given that sparrows ( $P$. domesticus, $P$. montanus, $P$. hispaniolensis) are the avian group that features most commonly in Barn Owl diet studies, it is interesting that the Amorgos owls make so little use of this abundant resource, presumably avoiding hunting in and around the village despite the proximity of the caves to Langada.

\subsection{Other taxa}

Rodents and shrews are normal components of Barn Owl diet (e.g. Romano et al. 2020) and will not be discussed further here, although some data of taphonomic interest may be extracted from the material at a later date (but see below).

Lizards are rarely an important constituent of the diet (ibid.), though geckos are a known if in- frequent component of Barn Owl prey (Roulin \& Dubey 2012), notably in Greece on Antikythera and Milos islands (Alizivatos et al. 2005, Alizivatos \& ANDriopoulos 2016), but no lacertids were recorded for Greece by Roulin \& Dubey (2012). However Овuch \& Benda reported unidentified lacertids from Crete, and Lacerta trilineata was found in pellets on Milos by Alizivatos \& Andriopoulos (2016); our Podarcis appear to be the first confirmed wall lizards found in Greek Barn Owl pellets.

Dung beetles, which are nocturnal, feature quite regularly (e.g. DenYs et al. 2017), though their total contribution is small.

\subsection{Prey proportions and bone survival}

It is clear from the data that the cave floor held far more rat and bird bones, and fewer Wood Mice and House Mice, than would be expected from the ratios in the complete pellets found in the same cave (Table 3). While changes in hunting behaviour over time cannot be ruled out, we think the explanation largely lies in the relative robustness of bones of different species. Rat bones, even the frequent juve- 
niles, are bulky, so slower to degrade (though many are eroded), while the bird bones found are noticeably better preserved overall in this environment than their rodent equivalents, hence both these taxa will have above-expected proportions. House Mice bones seem particularly degradable (few jaws are intact) while Wood Mice are intermediate, but many more are found damaged than those of the larger Rock Mice, as previously noted (CHEKE \& AsHCROFT 2017). Shrew jaws seem robust and are generally in good condition, though the proportion in pellets and loose is the same, as it is with Rock Mice. In the circumstances of this particular cave, trampling by goats would seem to be the main agent of bone deterioration, followed by the action of goat urine and faeces, aided by rainwater blown in during winter, which probably explains the lack of bones below the surface. Surface bones would rapidly dry out, those below would presumably remain wet and decay.

In addition to chemical erosion post-ejection, DenYs et al (2017) found that small mammal bones were more likely to be more damaged by digestion prior to ejection than bird bones, another indication of their greater susceptibility to forces of degradation. However they did not separate rodents and shrews in their analysis; our data show shrew bones as being as resistant as birds, suggesting contrast with rodents is sharper than DENYs et al.'s results imply. They also looked at which bones were most likely to survive 'processing' by Barn Owls (and other raptors) and, albeit on a much smaller sample than ours, came up with quite different proportions (Table 4). However they were sampling at nest sites, where Barn Owls dismember prey before feeding it to their young, whereas adults feeding themselves, as in our Amorgos sites, swallow most prey whole (BUNN et al. 1982, TAYLOR 1989). In their study, leg bones were more likely to survive than wing bones, in contrast to our data where humeri and ulnae were much more frequent than femur and tarsus elements amongst the loose bones. Hence in abandoned sites or zooarchaeological collections these different proportions may indicate whether the site was a roosting or nesting area.

In a similar pellet vs sediment study from Ibiza (Sommer et al. 2005), no such differences were found in the proportion of bird bones, and the reverse effect in rat and mouse bones proportionately far fewer rat bones in the sediment than in pellets, and far more Mus bones (of two species in both genera). The authors did not discuss the compositional discrepancies, nor did they publish the proportions of different bone types within totals of mammal and bird taxa.

\section{Conclusion}

Our data set of 39 species appears to be the most diverse range of birds for a single site recorded for Barn Owls anywhere, $51 \%$ of the total diversity of small passerines (and Wryneck) recorded for the island (77 species; CHeKe et al. 2020). While eating mainly rodents as elsewhere, Barn Owls on north-eastern Amorgos also target an unusually wide range of passerine migrants to the island, $19 \%$ of individual vertebrate prey items in Dhri Cave D), although the percentage in fresh pellets in the cave was only $4 \%$; for all local pellets it was 9\% (Table 1). Apart from the case discussed in Ibiza/Formentera, this breadth of avian prey does not seem to occur elsewhere in Europe; indeed in most of mainland Europe birds hardly feature. For example, the massive study in France by GUÉRIN (1928) found only a handful of birds (Chaffinch, sparrows Passer sp.) in hundreds of rodent and shrew items, though one exceptional site, out of 19 studied, in the French Pyrenees has yielded a high percentage of birds (77.6\%; LiBoIs 1983), but the birds were apparently not fully identified to species, though $77 \%$ of them were sparrows Passer spp. A big survey in Britain only $2 \%$ by number of prey was birds (Glue 1974); in central Italy ZAGORŠEK (2018) found no birds at all, though up to $3 \%$ were recorded in the Rome area by Salvati et al. (2002). A meta-analysis in Ireland found birds ranged from $0.2 \%$ in areas with both invasive shrews Crocidura russula and voles Myodes (ex-Clethrionomys) glareolus, to $3.5 \%$ in areas yet to be reached by these animals (SMIDDY et al. 2018); 22 bird species were recorded from 29 studies. Further east in mainland Europe, OBUCH et al.'s meta-analysis of $21516^{\text {th }}$ century to modern sites in Slovakia found 53 bird species overall, but with low percentages and diversity per site, and in Bulgaria Milchev et al. (2006) recorded 40 species over 28 sites. 
A. S. Cheke, J. P. Hume: The diet, and pellet residue taphonomy, of Barn Owls Tyto alba on a Greek island reveals an exceptional diversity of avian prey

Overall the low proportion of birds per site is true throughout the world range (Romano et al. 2020), however in North Africa, the Middle East and Pakistan birds can form much of the diet, with $100 \%$ taken in one study in Tunisia (see discussion in Bunn et al. 1982: 90). While in Pakistan birds can make up 30\% (NADEEM et al. 2012), only four species were taken and one (Common Mynah Acridotheres tristis) predominated; in Algeria up to 36 species can be involved (over 19 sites, RiHane 2003, 2004), though House Sparrows made up $71 \%$ of the avian catch, and $100 \%$ in another study (Hadjoudj et al. 2012). Studies by Овuch \& BENDA (2009) yielded 64 avian prey species spread over 27 sites in several countries in southern Europe, Israel and Egypt, the maximum numbers at one site being 20 (perhaps up to 25) in Israel; ОвUCH (2018) found site maxima of 16 and 19 in sites in Jordan, though the total over 10 sites in that country was 43 species. We have not been able to review the whole enormous literature on Barn Owl diet (see Romano et al. 2020), but have attempted to find studies where birds have featured significantly to compare with ours.

Clearly Barn Owls are adaptable and opportunistic, and have been recorded elsewhere targeting wintering thrushes in communal roosts, and roosting or urban aggregations of sparrows, hirundines, starlings, finches, larks, buntings and mynas (Milchev et al. 2006, Rahine 2003, 2004, NADEEM 2012). Chaffinches and possibly thrushes and Corn Buntings appear to have such roosts in Amorgos (ASC pers. obs.), but most of the species taken do not roost communally. It would appear that in Amorgos the owls find many migrants an easy target, though the variety remains unexplained; however the accumulation on the cave floor may represent a longer time series, and thus more opportunity, than in other reported studies.

Our study, and likewise those of others cited with high bird catches, shows that Barn Owl pellets should be included when investigating bird distribution and potentially also abundance, in addition to being a well-established method of sampling mammals. Furthermore, and to facilitate similar studies in the future, it is hoped that the photos of humeri will aid others in identifying birds in European owl pellets - many previous researchers have simply left avian remains as 'birds' with little or no further identification.

In analysing bones found loose on the floor of a roosting site of any pellet producing predator, it is important to take into account the relative deterioration rate of bones from different species, as our data shows. In our case there is a very significant bias in favour the avian bones and the largest rodent, and this may well be the case elsewhere. The proportion of different skeletal elements recovered, the 'taphonomic signature' (PoKInES \& PETERHANS 1997), rarely looked at, may also be significant for understanding the status of sites, abandoned or ancient, no longer in use (DENYs et al. 2017).

Acknowledgements: ASC particularly thanks Lonaï Jallais for showing him sites A and D, and sharing his observations on local Barn Owls, Linda Losito for identifying beetle remains, and Ruth Ashcroft for helping to scour the cave floor for bones; he is also indebted to the late Michael Rudd whose ancient village house he and Ruth Ashcroft had access to in Amorgos. We thank Joanne Cooper and Judith White for access to the skeleton collection in the Natural History Museum, Tring, $\mathrm{UK}$, and two anonymous referees whose comments led to useful untapped literature and a refinement of the paper. Also published after acceptance, Roulin's (2020) new monograph, which, while comparing Barn Owl diets worldwide, does not drill down into the kind of detail we present here.

\section{Postscript}

Since this paper was submitted, reviewed and accepted, an important paper with direct bearing on our results has been published. In a meta-analysis covering Mediterranean islands from Sardinia down to tiny Espartar (0.2 ha, Balearics) JANžEKovič \& KLENOvŠEK (2020) found that, in addition to a general trend of birds and reptiles being taken more than on mainland Europe, "diet diversity was greater on the larger Mediterranean islands. However, a more diverse diet did not mean a higher number of taxa, but a wider range of abundant and evenly represented taxa. The smaller the islands, the more birds and reptiles were consumed, compared to higher proportions of mammals on the larger islands. These findings support the idea of barn owls' feeding flexibility and opportunistic predator 
behaviour". The results were largely independent of human urbanisation and island isolation. Our results emphasize this pattern, and as Tina Klenovšek commented to ASC (email 21.09.2020) "What a coincidence. I am really sorry we could not use your results in our meta-analysis. They would fit so well into our findings".

\section{Povzetek}

Raziskani so bili izbljuvki pegaste sove Tyto alba in njihovi ostanki (posamezne kosti) na jamskih tleh otoka Amorgos (Kikladi, Grčija). Sove so uplenile vsaj 39 vrst ptic, kot je bilo ugotovljeno na podlagi najdenih nadlahtnic. Poleg njihove glavne prehrane (podgan Rattus rattus, miši Apodemus spp. in hišnih miši Mus musculus) so sove ulovile še vrtne rovke Crocidura suaveolens, nekaj kuščaric in hroščev. Med pticami so bile z nekaj izjemami prav selivke tiste, ki so bile najpogostejši plen pegaste sove, medtem ko so bile ptice stalnice zastopane v manjšem delu. $\mathrm{V}$ primerjavi s podobnimi raziskavami je slednja razkrila verjetno največji razpon različnih vrst ptic $\mathrm{v}$ izbljuvkih pegaste sove na posamezni lokaliteti. Ugotovljene so bile znatne razlike $\mathrm{v}$ deležu vrst $\mathrm{v}$ taksonih med izbljuvki in njihovimi ostanki (posamezne kosti), najverjetneje zaradi razlik $\mathrm{v}$ njihovem razkroju. $V$ pomoč pri drugih raziskavah so v članek vključene vse fotografije nadlahtnic.

\section{References}

Alivizatos H., Goutner V., Zogaris S. (2005): Contribution to the study of the diet of four owl species (Aves, Strigiformes) from mainland and island areas of Greece. - Belgian Journal of Zoology 135 (2) : 109-118.

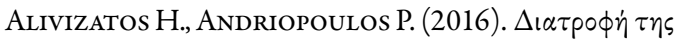

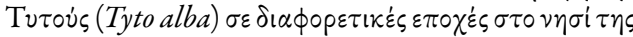
Mindov [Diet of the barn owl (Tyto alba) in different seasons in Milos island]. - Poster presentation at the 8th Panhellenic Ecology Conference, October 20-23, 2016 Thessaloniki, Greece.

Bontzorlos V. A., Peris S. J., Vlachos C. G., BaKaloudis D. E. (2005): The diet of barn owl in the agricultural landscapes of central Greece. - Folia Zoologica 54(1-2): 99-110.

Bosé, M., \& Guidali, F. (2001). Seasonal and geographic differences in the diet of the barn owl in an agro-ecosystem in northern Italy. - Journal of Raptor Research, 35(3): 240-246.
Brown R., Ferguson J., Lawrence M., Lees D. (1987): Tracks signs of the birds of Britain and Europe. An identification guide. - AC Black/Christopher Helm, London.

Bunn D. S., Warburton A. B., Wilson T. D. S. (1982): The Barn Owl. - T\&AD Poyser, London.

Chene A.S., Ashcroft R. E. (2016 ['2015']): Vocal gatherings of Blackcaps Sylvia atricapilla in olive trees on a Greek island. - Rivista Italiana di Ornitologia Research in Ornithology 85(2): 36-37.

Cheke A. S., AshCroft R. E. (2017): Mammals and butterflies new to Amorgos (Kiklades), with notes on reptiles and amphibians. - Parnassiana Archives 5: 11-27.

Cheke A. S., Tsiakiris R., Christopoloulos A., Ashcroft R. E. (2020): The breeding birds of a small Aegean island (Amorgos, Cyclades, Greece), with details of changes over 25 years. - Parnassiana Archives 8, Supplement 2.

Denys C., Stoetzel E., Andrews P., Bailon S., Rihane A., Huchet J. B., Fernandez-Jalvo Y., LAROULANDIE, V.(2017): Taphonomy of small predators multi-taxa accumulations: palaeoecological implications. - Historical Biology 30: 868-881 (print ed. 2018).

Dimaki M., Papazoglou C., Akriotis T. (2006): Bird ringing in Antikythira island (S. Greece). - The Ring 28(1): 85-94.

Gavalas I. (2014): Flying over the Aegean. A guide to the birds of Iraklia and the nearby islets. - Wild Greece Editions, Athens.

Glue D. (1974): Food of the Barn Owl in Britain and Ireland. - Bird Study 21: 200-210.

Goutner V., Alivizatos H. (2003): Diet of the Barn Owl (Tyto alba) and Little Owl (Athene noctua) in wetlands of northeastern Greece. - Belgian Journal of Zoology 133(1): 15-22.

GuÉRIN G. (1928): Régime et croissance de l'effraye commune Tyto alba alba (L. ) en Vendée. - Thesis, University of Poitiers. Imprimerie Henri Lussaud, Fontenay-le-Comte.

Guerra C., García D., Alcover J. A. (2014): Unusual foraging patterns of the barn owl, Tyto alba (Strigiformes: Tytonidae), on small islets from the Pityusic archipelago (Western Mediterranean Sea). - Folia Zoologica 63(3): 180-187.

Hadjoudj M., Manaa A., Sekour M., Souttou K., Merzouki Y, DoumandjI S. (2012): Place des rongeurs dans le régime trophique de la chouette effraie Tyto Alba dans la région de Touggourt (Algérie). - Revue des BioRessources 2(1): 33-40

HANDrinos G., AKriotis T. (1997): The birds of Greece. - AC Black/Christopher Helm, London.

JANŽEKOVIČ, F. \& KLENOVŠEK, T. (2020): The biogeography of diet diversity of barn owls on Mediterranean islands. Journal of Biogeography 2020;00:1-9. 
A. S. Cheke, J. P. Hume: The diet, and pellet residue taphonomy, of Barn Owls Tyto alba on a Greek island reveals an exceptional diversity of avian prey

JÁNOssy G. (1983): Humeri of Central European passerines. - Fragmenta Minerologica et Palaeontologica 11: $85-112$.

LAWRENCE M. J., Brown R. W. (1973): Mammals of Britain. Their tracks, trails and signs. Rev. ed. Blandford Press, London.

Libois R. M, Fons R., Saint-Girons, M. C. (1983): Le régime alimentaire de la chouette effraie Tyto alba dans les Pyrénées-Orientales. Etude de variation géographique. - Revue d'Ecologie (Terre et Vie) 37: $187-217$

MASSETI M. (2012): Atlas of terrestrial mammals of the Ionian and Aegean islands. - Walter de Gruyter, Berlin.

Milchev B., Boev Z., Georgiev V. (2006): Birds in the diet of Barn Owl Tyto alba in SE Bulgaria. - Acrocephalus 27: 271-275.

Nadeem M. S., Shah S. I., Kayani A. R., Imran S. M. K., Mahmood T. (2012): A comparative study of the diets of barn owl (Tyto alba) and spotted owlet (Athene brama) inhabiting Ahmadpur East, Southern Punjab, Pakistan. - Animal Biology, 62(1): $13-28$.

Obuch J., Benda P. (2009): Food of the Barn Owl (Tyto alba) in the Eastern Mediterranean. - Slovak Raptor Journal 3: 41-50.

Obuch, J., Danko Š., Noga M. (2016): Recent and subrecent diet of the barn owl (Tyto alba) in Slovakia. - Slovak Raptor Journal, 10: 1-50.

Овисн, J. (2018): On the diet of owls (Strigiformes) in Jordan. - Slovak Raptor Journal 12: 9-40.

Perrins C. M. (1987): Collins new generation guide. Birds of Britain and Europe. - Collins, London.

Pokines, J. T., \& Peterhans, J. C. K. (1998): Barn owl (Tyto alba) taphonomy in the Negev Desert, Israel. Israel Journal of Ecology and Evolution, 44(1), 19-27.

Rinane, A. (2003): Contribution à l'étude du régime alimentaire de la Chouette effraie Tyto alba (Strigiformes, Tytonidae) dans les plaines semi-arides du Maroc atlantique. - Alauda 71: 363-369.

Rihane, A. (2004): Contribution à l'étude du régime alimentaire de la Chouette effraie Tyto alba (Strigiformes, Tytonidae) dans les plaines semi-arides du Maroc atlantique. - Doctoral thesis, Université Hassan Ii- Mohammedia Faculté des Sciences et Techniques. $270 \mathrm{pp}+$ annexes.

Romano A., SÉCHAUd R., Roulin A. (2020): Global biogeographical patterns in the diet of a cosmopolitan avian predator. - Journal of Biogeography 47 (7): 1467-1481.

Rosenbaum G., Ring U., Kühn A. (2007): Tectonometamorphic evolution of high-pressure rocks from the island of Amorgos (Central Aegean, Greece). - Journal of the Geological Society, London 164: 425-438.
Roulin A., Dubey S. (2012): The occurrence of reptiles in Barn Owl diet in Europe. - Bird Study 59: 504-508

Roulin A. (2020): Barn Owls. Evolution and Ecology, with Grass Owls, Masked Owls and Sooty Owls. Cambridge University Press, Cambridge UK. 297pp.

Salvati, L., Ranazzi, L., \& Manganaro, A. (2002). Habitat preferences, breeding success, and diet of the Barn Owl (Tyto alba) in Rome: Urban versus rural territories. - Journal of Raptor Research 36(3): 224-228.

Smiddy P., SLeEMan D. P., O'Halloran, J. (2018): Barn Owl Tyto alba diet in Ireland: a review. - Irish Birds 11: 39-48.

Snow, D. W., Perrins, C. M. (eds. ) (1998): The Birds of the Western Palearctic. Concise Edition. -Oxford University Press, Oxford. 2 vols.

Sommer, R., Zoller, H., Kock, D., BöHme, W., Griesau, A. (2005): Feeding of the barn owl, Tyto alba with first record of the European free-tailed bat, Tadarida teniotis on the island of Ibiza (Spain, Balearics). Folia Zoologica 54 (4): 364-370.

Taylor, I. R. (1989). The Barn Owl. - Shire Publications, Princes Risborough, UK. 24pp.

TAYloR, I. [R. ] (1994): Barn Owls. Predator-prey relationships and conservation. - Cambridge University Press, Cambridge, UK 304pp.

TAYLOR, I. R. (2002): Occupancy in relation to site quality in Barn Owls (Tyto alba) in south Scotland. - Chapter 2, pp. 30-41. In Newton I, Kavenagh R, Olsen J., Taylor I. (eds. ) Ecology and conservation of owls. CSIRO Publishing, Collingwood, Victoria, Australia.

Villa, A., Daza, J. D., Bauer, A. M., Delfino, M. (2018): Comparative cranial osteology of European gekkotans (Reptilia, Squamata). - Zoological Journal of the Linnean Society 20: 1-39.

ZAGORŠEK T. (2018): A contribution to the knowledge of diet composition of the Barn Owl Tyto alba in the area of Pisa (Italy). - Acrocephalus 39: 171-176.

Prispelo / Arrived: 19. 11. 2019

Sprejeto / Accepted: 22. 9. 2020 